\title{
HALLAZGOS Y DESAFÍOS DE LA TUTORÍA DEL TRABAJO DE GRADO DESDE UN ESTUDIO DE CASO: PUNTO DE PARTIDA PARA PROPONER COMPETENCIAS DEL TUTOR
}

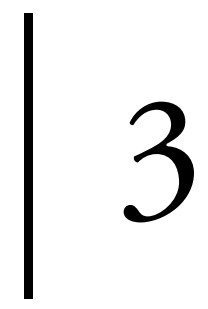

\author{
Martha Hortensia Arana Ercilla ${ }^{1}$ \\ Carlos Miguel Acosta Arévalo ${ }^{2}$ \\ Vicente Hernán Ibarra Argoty ${ }^{3}$ \\ Daiana Ivonne Reyes García ${ }^{4}$
}

\section{Preámbulo a la investigación en educación para la educación de la investigación}

La calidad de los trabajos de grado ha sido una preocupación permanente en la Escuela Militar de Cadetes "General José María Córdova" (Esmic), en directivos, tutores y estudiantes. Sin embargo, estos últimos no siempre lo asumen de manera responsable, pues postergan el proceso de investigación formativa necesario para realizar el trabajo de grado, lo cual evidencia que tienen una confianza desmedida

1 Economista. Doctorado y Posdoctorado en Educación, Especialista en Economía y Gestión de la Ciencia y la Tecnología de la Universidad de La Habana, Cuba. Profesora titular, investigadora asociada de Colciencias. Profesora y asesora del Área de Investigación de la Facultad de Ciencias Militares de la Escuela Militar de Cadetes General "José María Córdova” de Colombia. Profesora titular de la Maestría en Educación de la Universidad Sergio Arboleda.

2 Oficial de la Reserva Activa del Ejército Nacional de Colombia, Profesional en Ciencias Militares de la Escuela Militar de Cadetes “General José María Córdova”, Especialista en Docencia Universitaria, del Centro de Educación Militar. Vicedecano de la Facultad de Ciencias Militares. Hizo parte del equipo que redimensionó el currículo por competencias del Programa de Ciencias Militares de la ESMIC, aprobado por el SEFA del Comando General de las Fuerzas Militares y presentado ante el Consejo Nacional de Acreditación del Ministerio de Educación Nacional.

3 Oficial de la Reserva Activa del Ejército Nacional de Colombia, Profesional en Ciencias Militares de la Escuela Militar de Cadetes "General José María Córdova”, Abogado de la Universidad La Gran Colombia, Máster en Análisis y Prevención del Terrorismo de la Universidad Rey Juan Carlos (Madrid-España), Especialista de Administración de Recursos Militares para la Defensa, del Centro de Educación Militar. Profesor Militar de Tercera Categoría y Profesor Asociado; en la actualidad se desempeña como Asesor del Área de Formación Profesional General e Investigador de la Facultad de Ciencias Militares.

4 Politóloga con énfasis en Relaciones Internacionales de la Pontificia Universidad Javeriana, Especialista en Políticas y Asuntos Internacionales, Especialista en Derecho internacional Aplicable a los Conflictos Armados de la Escuela Militar de Cadetes "General José María Córdova”, Magister en Seguridad y Defensa de la Escuela Superior de Guerra; en la actualidad es la Asesora Académica de la Facultad de Relaciones Internacionales de la Escuela Militar. 
en que el tiempo les va a alcanzar y por eso desaprovechan las oportunidades que les brinda la Escuela durante la carrera para que lo hagan de forma satisfactoria. Asimismo, aunque este ejercicio de formación académica inicia desde los primeros semestres con la presencia de un tutor, los estudiantes no planean a conciencia el tiempo con un cronograma preciso ni emplean racionalmente las posibilidades de colaboración que les ofrece el trabajo en equipo en que este se realiza 5 .

Por este camino, el desasosiego y la preocupación que les produce a los tutores esta situación no solo llevan a algunos a perder la perspectiva de que son educadores, sino que generan un debate formal e informal sobre quiénes son los responsables de los limitados conocimientos en investigación que evidencian los estudiantes y de sus actitudes ante la tarea, que se expresan además en falta de compromiso, facilismo y superficialidades.

Esta problemática contrasta con el espíritu de investigación formativa que tiene el trabajo de grado, pues se espera que el estudiante demuestre, a través del objeto de estudio y la solución del problema que ha definido, todos sus conocimientos anteriores con rigor, coherencia y ética, aspectos de una elemental cultura de las ciencias militares y de su futura profesión. En consecuencia, quizá la principal tarea sea generar actitudes y comportamientos en los estudiantes hacia la investigación como método de la ciencia para identificar, pensar y solucionar problemas.

Es necesario destacar que la Esmic, como pocas instituciones de educación superior, acompaña al estudiante en un proceso académico de investigación formativa que empieza desde los primeros semestres, con asignaturas que se traducen en talleres creativos para el desarrollo de la competencia de lectoescritura. Posteriormente, la formación se afianza a través de la inmersión en los fundamentos de la ciencia y la metodología de la investigación y la estadística, hasta que se asignan los tutores como guías de los trabajos de grado. No obstante, subyacen dificultades en la calidad de los documentos que evidencian la falta de competencias investigativas.

Precisamente, este es el contexto en el cual se realizó el trabajo que se presenta en este capítulo, el cual continúa una secuencia de estudios sobre la investigación formativa y la educación científico-tecnológica e investigativa (CTI), cuyo propósito ha sido identificar las limitaciones en el aprendizaje para desarrollar competencias que le permitan a los estudiantes elaborar trabajos de grado de calidad.

5 Véase los resultados de la investigación de proyecto institucional (2012) titulada "La formación de valores de responsabilidad y trabajo cooperativo en equipo, en el proceso de investigación para el trabajo de grado: Un estudio de caso único", que corresponde al cuarto capítulo del libro Educación cientifica y cultura investigativa para la formación del profesional en ciencias Militares de Colombia" (Arana et al., 2013, p. 147). 
Por lo tanto, el objeto de estudio de la investigación es analizar la formación por competencias de investigación en los estudiantes durante las diferentes etapas del proceso: La formación metodológica desde el aula, la tutoría del trabajo de grado, hasta la entrega del documento final escrito y su sustentación. Así, la hipótesis de investigación es que existen limitaciones pedagógicas y de gestión educativa que están afectando la calidad de los trabajos de grado.

El proyecto de investigación del cual forma parte este estudio está compuesto por tres etapas, las cuales tiene en común dos aspectos: (1) El objeto de estudio, es decir, analizar el proceso de investigación formativa y sus resultados en la Esmic con el propósito de determinar las limitaciones pedagógicas y de gestión educativa que existen. (2) El tipo de investigación: Una exploración descriptiva de lo que acontece sobre la investigación formativa en la enseñanza de la metodología de investigación, la realización de las tutorías de trabajos de grado y la calidad de los trabajos de grado para su sustentación. Sin embargo, cada etapa contó con su propio diseño metodológico, como se presenta en la figura 1.

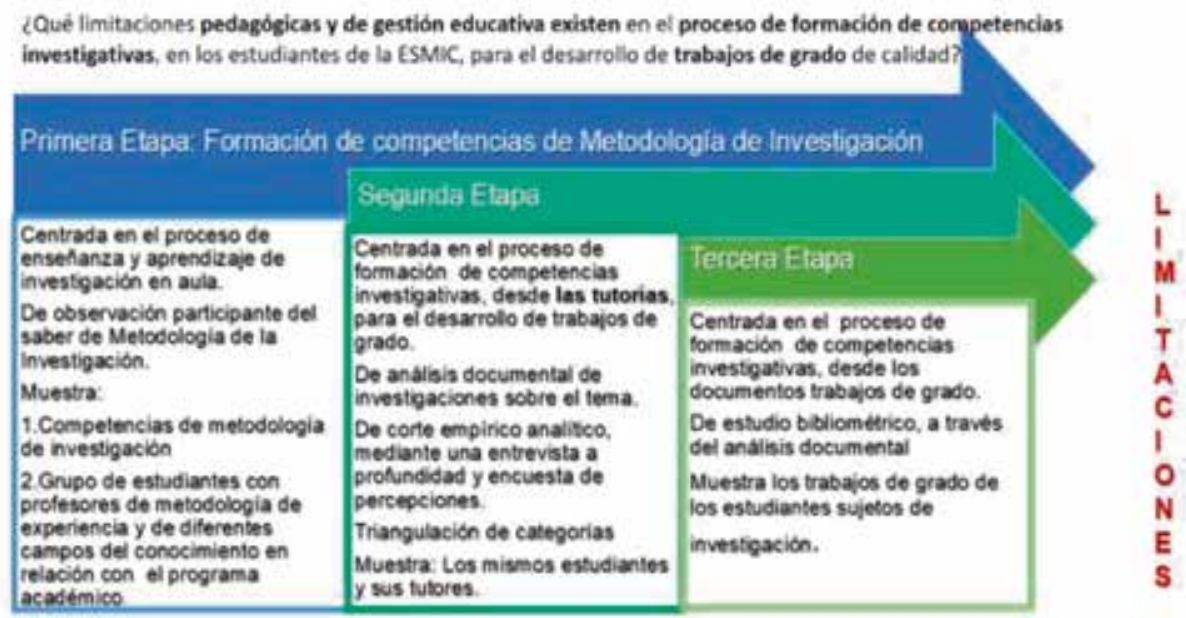

Figura 1. Etapas del proceso de indagación para determinar las limitaciones existentes para el desarrollo de trabajos de grado de calidad

Fuente: Elaborada por los autores.

Específicamente, el presente capítulo se centra en la segunda etapa, lo cual significa que, por una parte, identifica la tutoría como una estrategia pedagógica en la investigación formativa para la elaboración de los trabajos de grado en la Esmic, y, por otra, propone competencias de investigación formativa que orienten el proceso tutorial del trabajo de grado desde el modelo pedagógico de la formación del futuro 
oficial del Ejército Nacional. En este sentido, los resultados que se exponen corresponden a la pregunta general de investigación: ¿Qué limitaciones pedagógicas y de gestión educativa existen en el proceso de formación de competencias investigativas desde las tutorías para que los estudiantes de la Esmic desarrollen trabajos de grado de calidad?

Ahora bien, también es importante mencionar que este proyecto surgió de la búsqueda permanente de las limitaciones, las percepciones, las opiniones, las concepciones y los enfoques sobre la investigación formativa y la cultura de la investigación que circulan en la Esmic, de tal manera que fuera posible proponer soluciones a los problemas identificados y contar con un punto de partida para reconocer que solo desde la mirada pedagógica, educativa y de gestión en la educación es posible cumplir este objetivo. Así, como se mencionó, en este proceso de indagación constante se han desarrollado varios proyectos de investigación ya concluidos que arrojan información y conocimientos para entrar en esta nueva etapa de investigación pedagógica desde y en el aula (Arana et al., 2013). Los títulos de estos proyectos son los siguientes: "La educación científica y tecnológica del cadete a través del desarrollo de estrategias de formación por competencias de investigación"; "Análisis de las competencias de investigación a través de un estudio bibliométrico de los trabajos de grado del 2008 y 2009 de la Facultad de Ciencias Militares de la Esmic"; "Estudio comparativo de las competencias investigativas en los trabajos de grado del año 2009 y los informes de investigación finales de la materia metodología de investigación del año 2011 por medio de un análisis bibliométrico"; "Rutas exploradas de la formación por competencias en la Esmic: Una mirada a la construcción del espíritu militar"; "Evaluación de competencias transversales de lectoescritura en el Área de Investigación en la formación de profesionales en ciencias militares"; "La formación de valores de responsabilidad y trabajo cooperativo en equipo en el proceso de investigación para el trabajo de grado: Un estudio de caso único"; "Diseño de una metodología de evaluación de la gestión para la consolidación de la cultura investigativa. Investigadores"; "Evaluación de la cultura de la investigación".

En estos trabajos se confirma que actualmente existen serios problemas de la educación de la ciencia, la tecnología y la investigación que impiden generar la cultura de la investigación a través de la formación y el aprendizaje de las competencias de investigación formativa, así como en las investigaciones realizadas en el país. Entre estos problemas se pueden mencionar los siguientes: Las comprensiones tradicionales de la ciencia, la tecnología y la investigación; la aceptación acrítica de las corrientes relativistas actuales, que niegan la ciencia como nivel de generali- 
zación en las ciencias sociales; la desactualización y desinterés en el conocimiento científico, la formación profesional y los conocimientos y saberes pedagógicos; el supuesto o mito de que la investigación formativa es solo el resultado del quehacer metodológico, de tal manera que se pierde su epistemología y axiología; el pragmatismo e inmediatismo en la solución de problemas que impide pensar responsablemente desde el método científico; las limitaciones en el saber cooperar y trabajar en equipo; las dificultades en la divulgación científica y su lectura; la restringida relación entre la ciencia y la formación profesional; la deficiente cultura general para pensar con profundidad y encontrar soluciones creativas; finalmente, la carencia de una gestión de la investigación desde la participación y la contextualización de los ambientes educativos en el ámbito institucional que garantice este proceso. Todo esto se manifiesta en la baja calidad de los trabajos de grado, los conflictos académicos entre los profesores de metodología y los tutores, así como en la falta de estrategias pedagógicas para desarrollar la investigación formativa, entre otros aspectos.

\section{Presupuestos del proceso de investigación}

Como punto de partida, en este trabajo se tuvieron en cuenta cinco presupuestos, los cuales se toman del proyecto de investigación denominado "La formación de valores de responsabilidad y trabajo cooperativo en equipo en el proceso de investigación para el trabajo de grado: un estudio de caso único" (Arana et al., $2018)^{6}$.

No obstante, antes de listarlos, es importante mencionar que el modelo pedagógico de la Esmic (caso de estudio) se basa en el aprendizaje significativo con un enfoque por competencias. Así mismo, privilegia la interiorización de los valores profesionales y el desarrollo de actitudes y comportamientos desde las dimensiones del ser, el saber, el saber hacer y el saber convivir (Esmic, 2018). En concordancia con esta perspectiva, los principios de la investigación son los siguientes:

- La investigación pedagógica y educativa debe estar ligada, hasta donde sea posible, al aula, a la práctica educativa, a los significados y comprensiones que tienen los educadores sobre la formación, a los modelos pedagógicos, a la cultura general y, en el caso de estudio, a la cultura de la investigación. Por lo tanto, este accionar puede conducir a la investi-

6 Este consistió en un estudio de campo en el aula, con observación participante, para evaluar las competencias de investigación en las dimensiones del ser y el convivir. 
gación científica hacia nuevas propuestas teóricas en la pedagogía y la educación, así como a generar innovaciones y nuevas prácticas que solucionen los problemas. De la misma manera, también incentiva las transformaciones metodológicas y de evaluación para renovar o actualizar el currículo, o para crear nuevas estrategias didácticas en relación con la educación de calidad.

- Asimismo, este estudio se fundamenta en la idea de que los procesos pedagógicos no son unilaterales ni siguen una dirección determinada - por ejemplo, del profesor al estudiante-, sino que se caracterizan por tener diferentes direcciones y relaciones que surgen como producto de los intereses y las motivaciones de los estudiantes hacia el conocimiento, así como del compromiso y la responsabilidad del profesor con este proceso, lo cual constituye el sentido central de la educación y la formación de profesionales. Por lo tanto, solo la práctica permite comprender de qué manera se manifiesta dicho propósito.

- Otro presupuesto es que el proceso de formación se produce en ambientes culturales determinados, de manera que se deben tener en cuenta para comprenderlo a fondo, así como es necesario reconocer las relaciones interpersonales para mejorarlo y transformarlo. En consecuencia, el aprendizaje se entiende como una construcción cultural caracterizada por el intercambio no solo de conocimientos entre personas, sino también de significación en el sujeto de aprendizaje en sí mismo, de desarrollo de su personalidad y de preparación para la vida profesional. Valga añadir, así también del profesor o tutor.

- El siguiente principio consiste en considerar que los procesos educativos son en sí mismos objetos de investigación en cuestiones como: El entorno del aprendizaje, las relaciones que se establecen, los sistemas de conocimientos que se seleccionan, los comportamientos que se asumen, entre otros aspectos.

- Finalmente, el estudio reconoce el diagnóstico como el procedimiento mediante el cual es posible conocer el estado de un proceso u objeto de educación en un momento determinado y con base en un ideal que se ha definido con anterioridad. Su importancia educativa consiste en que satisface la necesidad de acceder a los significados y sentidos de los hechos, así como a las situaciones que involucran a los sujetos participantes, al tiempo que permite identificar la interacción y el sistema de relaciones que establecen entre ellos en un acontecimiento determi- 
nado o las tendencias de su comportamiento ante esas circunstancias. Se considera, además, que el diagnóstico es también una reflexión activa y consciente, que caracteriza una realidad y que se convierte en un punto de partida necesario para que los profesores enseñen y los estudiantes aprendan.

Ahora bien, la investigación se inscribe en un paradigma interpretativo y cualitativo, de tipo exploratorio-descriptivo y de carácter empírico analítico. A través de un trabajo de campo y la aplicación de una encuesta de percepciones, el estudio explora los procesos tutoriales de trabajo de grado desde la mirada de los tutores y los estudiantes de la muestra observada en la primera etapa, quienes cursaban el séptimo semestre y, por lo tanto, estaban realizando la investigación y elaboración del trabajo de grado para presustentación. Asimismo, a los tutores de los estudiantes se les hizo una entrevista en profundidad, la cual permite comparar opiniones y percepciones de su labor educativa.

Para elaborar la encuesta de percepciones y la entrevista a profundidad se revisaron las investigaciones disponibles sobre tutorías, investigación formativa y trabajo de grado. Empleando la técnica de análisis de contenido, se logró una amplia comprensión de los problemas estudiados y sus polémicas, así como de las nuevas construcciones conceptuales y prácticas educativas —elementos preponderantes del objeto de investigación-. Este ejercicio permitió identificar las categorías para construir el cuestionario de cada instrumento y su posterior estudio empírico en los sujetos seleccionados.

Sin embargo, antes de analizar las tutorías como el espacio donde convergen los intereses académicos y pedagógicos del tutor y del tutorado, primero se expone cómo asumió esta investigación el concepto de percepción para construir el instrumento adecuado, de tal manera que permitiera entender la mirada de cada uno de estos dos actores en relación con las tutorías y, así, describir las limitaciones existentes y formular propuestas efectivas, acordes con las necesidades del proceso de construcción de los trabajos de grado.

\section{Sobre la percepción en la investigación}

La percepción es un tema muy debatido a través de la historia de la filosofía, la psicología, la pedagogía, el arte y, hoy, la neurociencia. Diferentes enfoques sostienen que la percepción es la conciencia de una sensación, es un proceso psicofísico por el cual el sujeto transforma las impresiones sensoriales en objeto sensible conocido. En la percepción también influyen múltiples elementos del sujeto consciente, 
como la memoria, la experiencia, los conceptos previos, entre otros. Además, la percepción permite reconocer una imagen como representación mental del objeto y, por tanto, es el acto, el producto de la imaginación reproductiva o creadora en relación directa con lo sensorial.

Así, es posible que sea analizada por diferentes especialistas, entre ellos el reconocido profesor, psicólogo y químico E. Bruce Goldstein (1999), quien destaca en su libro Sensaciones y percepciones:

Una de las grandes ilusiones de la vida es afirmar que la percepción es simple... Parece como si solo ocurrieran. Pero la facilidad con que percibimos el mundo oculta una gran cantidad de procesos complejos. El reconocimiento es nuestra capacidad de situar los objetos en categorías que le confieren un significado [...]. La acción sigue a la percepción y al reconocimiento como resultado de la percepción. (p. 15)

Otro autor reconocido es el historiador del arte Rudolf Arnheim (1995), psicólogo del arte en la Universidad de Harvard, que presenta en su libro El pensamiento visual algunas de sus principales tesis alrededor del tema:

La mente, para enfrentarse con el mundo, tiene que recoger información, tiene que llenar dos funciones, recoger información y procesarla, es decir, percepción y pensamiento, dos funciones que no pueden separase por la división del trabajo a la que estamos acostumbrados [...] solo porque la percepción capta tipos de cosas, esto es, conceptos, puede el material conceptual utilizarse para el pensamiento; e, inversamente, a no ser que el caudal sensorial permanezca presente, la mente no tiene con qué pensar. (p. 1)

Arnheim también señala que la causa de la limitada comprensión de la percepción fuera de la razón, asociada solo a los sentidos, hay que analizarla históricamente a partir de una corriente del pensamiento griego que desconfía en los sentidos y los separa de la razón, como ocurrió en el caso de los sofistas.

Por mi parte sostengo que el conjunto de las operaciones cognoscitivas llamadas pensamiento no son un privilegio de los procesos mentales ubicados por encima y más allá de la percepción, sino ingredientes esenciales de la percepción misma. Me refiero a operaciones tales como la exploración activa, la selección, la captación de lo esencial, la simplificación, la abstracción, el análisis y la síntesis, el completamiento, la corrección, la comparación, la solución de problemas, como también la combinación, la separación y la inclusión en un contexto. Estas operaciones no son la prerrogativa de ninguna de las funciones mentales; son el modo en el cual tanto la mente del hombre como la del animal tratan el material cognoscitivo a cualquier nivel. No existe diferencia básica en este respecto entre lo que sucede cuando una 
persona contempla directamente el mundo y cuando se sienta con los ojos cerrados y "piensa". (Arnheim, 1985, p. 13)

Más adelante agrega lo siguiente:

Por cognoscitivo quiero significar todas las operaciones mentales implicadas en la recepción, el almacenaje y procesamiento de la información: Recepción sensorial, memoria, pensamiento, aprendizaje. Esta utilización del término entra en conflicto con aquella a la que muchos psicólogos están habituados y que excluye de la cognición la actividad de los órganos de los sentidos. Refleja la distinción que estoy tratando de eliminar; por tanto, debo extender la significación de los términos "cognoscitivo" y "cognición", de modo que abarquen la percepción. De manera semejante, cómo eliminar la palabra "pensar" de lo que acaece en la percepción. No parece existir ningún proceso de pensar que, al menos en principio, no opere en la percepción. (p. 93)

Por su parte, desde los estudios actuales del cerebro, el notorio neurofisiólogo colombiano Rodolfo Llinás (1999) afirmó que "la percepción nace como la música de un piano, donde el sonido (la metáfora que representa la percepción) está generado por las cuerdas del piano (las propiedades intrínsecas), cuyo orden está especificado por la activación de las teclas (los sentidos)” (1999, p. 105).

Asimismo, el reconocido neurocientífico español Ignacio Morgado (2012), catedrático de psicobiología en el Instituto de Neurociencia de la Universidad Autónoma de Barcelona, señala en Cómo percibimos el mundo. Una exploración de la mente y los sentidos que

[1]a mente es el conjunto de funciones o procesos del cerebro, como sentir y percibir el propio cuerpo y el mundo en que vivimos, tener motivaciones y emociones, aprender y recordar, olvidar y sońar, hablar y comprender el lenguaje, etc., incluidas todas las formas posibles de pensamiento y entendimiento, este como la actividad mental que tiene lugar en ausencia de la propia cosa sobre la que se piensa. (p. 27)

Luego se refiere a que todos los procesos mentales están relacionados y ocurren de forma consciente o inconsciente, de manera que las emociones influyen en los sentimientos,

del mismo modo que lo hacen las percepciones y los sueños. Es decir, el cerebro, mediante la actividad electroquímica de sus neuronas, crea la mente y nos hace percibir lo que ocurre fuera y dentro de nuestro cuerpo de un modo especial y fascinante que no tiene por qué coincidir con la realidad misma, sea esta lo que sea. Ese modo especial no es otra cosa que la percepción consciente y sus contenidos. (p. 28) 
Por lo que se puede colegir, el concepto de percepción es entendido como una de las características del desarrollo del pensamiento y del conocimiento, que hace referencia a la construcción de entendimiento y puntos de vista sobre hechos y cosas. Es decir, un proceso mediante el cual el pensamiento integra los estímulos sensoriales sobre objetos, hechos o situaciones, provenientes del exterior y las transforma en totalidades organizadas y dotadas de significado para el sujeto. Al respecto, en "Psicología de la conciencia: conceptos, hipótesis y observaciones clínicas y experimentales", Morgano (2009) se refiere a la relación de la dimensión sensorial y las percepciones con la conciencia del ser humano:

[La percepción] es un estado de la mente subjetivo, cualitativo y unificado, que aporta flexibilidad al comportamiento. Los qualia son las cualidades sensoriales que componen la experiencia consciente. Integran una gran cantidad de información con carácter ejecutivo. La consciencia parece radicar fundamentalmente en la corteza cerebral, aunque el tálamo y los sistemas subcorticales de arousal podrían ser necesarios, pero no suficientes, para generarla. El cerebro podría generar consciencia mediante mecanismos de resonancia, sincronización y/o integración funcional de la actividad de las neuronas de diferentes regiones corticales y subcorticales. El cerebro humano podría no haber evolucionado lo suficiente para entender cómo la materia objetiva se vuelve imaginación subjetiva. (p. 251)

Cuando se refiere a las percepciones, este autor señala:

La mente, una entidad compleja y en cierto modo misteriosa, es lo más familiar y propio que tenemos, aquello con lo que cada uno de nosotros más se identifica. Funciona de tal modo que si abrimos los ojos en un día soleado sentimos que todo el paisaje que contemplamos está lleno de luz. Igualmente, el olor del desayuno matinal nos parece que está ahí fuera, saliendo de la taza de café caliente. Pero lo cierto es que esa luz y ese olor sólo existen en nuestra mente, pues son el modo en que el cerebro hace que percibamos las diferentes formas de energía que circundan nuestro entorno. Fuera de nosotros no hay luz, sólo energía electromagnética; ni olor, sólo partículas volátiles. Es decir, el cerebro crea la mente y nos hace percibir lo que ocurre fuera y dentro de nuestro cuerpo de un modo especial y fascinante que no tiene por qué coincidir con la realidad misma. Ese modo especial no es otra cosa que la percepción consciente y sus contenidos, un fenómeno que, además de dar sentido a nuestra vida, aporta flexibilidad al comportamiento y nos convierte en seres verdaderamente inteligentes. [...] Muchos procesos mentales tienen lugar de modo automático e inconsciente, pero la mayoría de ellos, como las percepciones, las emociones o la memoria, tienen también lugar de manera consciente. (Morgado, 2009, p. 251) 
Y continuando con su explicación, añade que

Cada experiencia consciente, sea simple o compleja, tiene una determinada característica, un modo particular de percibirse, diferente a cualquier otra. No es lo mismo percibir la rojez del rojo que el picante del picor, lo doloroso del dolor que la emoción de un premio, el sabor de una comida, que el malestar de la envidia, el sentir que uno es una persona física, que el estar enamorado, el vivir la realidad presente que el recordarla más tarde, etc. Hasta un águila o un cocodrilo, como cualquier otro animal con capacidad de consciencia, deben tener una percepción particular de ser lo que son y no otra cosa. (Morgado, 2009, p. 252)

En esta misma línea, la investigación sobre las percepciones en la educación científica e investigativa que se publicó en el libro Educación científica y cultura investigativa para la formación del Profesional en Ciencias Militares de Colombia (Arana et al., 2018) hace referencia al interés que existe en indagar la percepción de los estudiantes como primer nivel de conocimiento, de comprensión y punto de partida para la enseñanza y el aprendizaje con significado. A continuación, se presentan los argumentos que presenta ese trabajo:

[L]as percepciones son conocimientos que, para su correcta construcción, implican operaciones mentales en la recepción, el almacenaje y el procesamiento de la información, como la recepción sensorial, la memoria, el pensamiento y el aprendizaje, entre otros; el aprendizaje en la ciencia se produce como un proceso que va de la apariencia a la esencia, para el científico como un descubrimiento y para el estudiante como un proceso de aprendizaje adquirido a través de la enseńanza; conocer las apariencias permite un camino metodológico hacia la esencia del objeto de estudio, parte de las percepciones y sus apariencias o imágenes; estudio, a partir de las percepciones y sus apariencias; el proceso de enseñanza y aprendizaje parte de los conocimientos percibidos por el estudiante; es un acto cognitivo primario que implica la razón y las emociones, es decir, el pensamiento y la acción. (Arana et al., 2018, p. 137)

Como se mencionó anteriormente, con base en esta comprensión de la percepción se elaboró un cuestionario que permitió identificar las percepciones que tienen los estudiantes sobre la tutoría, el tutor y el trabajo de grado. Asimismo, se debe señalar que este instrumento también se basó en la metodología de la Red Iberoamericana de Indicadores de Ciencia y Tecnología (Ricyt, 2003) y su aplicación en diferentes estudios de Colciencias y de varias universidades, entre ellas la Esmic (2009-2010). En este caso particular, la metodología de Ricyt fue adaptada al estudio de la investigación formativa, específicamente, de la tutoría de trabajo de grado. Con este enfoque, la aplicación del cuestionario tuvo como finalidad conocer in situ las 
percepciones de los estudiantes para ahondar en los significados, intereses y actitudes que le atribuyen a la tutoría y las ideas que tienen para su mejoramiento.

En cuanto a la revisión de literatura mencionada, cabe señalar que se encontraron algunas investigaciones similares que han sido publicadas, entre ellas: “¿Cómo avanzar en la tutoría universitaria? Estrategias de acción: Los estudiantes tienen la palabra” (Martínez, Martínez \& Pérez, 2016), donde se cita a otros investigadores que destacan la importancia de identificar las percepciones e ideas de los estudiantes en los aspectos académicos que les atañen para pensar en las mejoras pertinentes.

Esta metodología ha sido aplicada en Colombia en diferentes estudios sobre las percepciones de la ciencia y la tecnología, que se refieren a un saber informativo y de significación que llegan al sujeto como reflejo de la realidad a través de la actividad social, es decir, a través de los medios masivos de comunicación, la educación y la vida cotidiana (Arana $\&$ Rodríguez, 2007). Esta estrategia se basa en los Estudios de Ciencia, Tecnología y Sociedad (CTS), que se expresan en el documento "Resultados de la Encuesta de Percepción Pública de la Ciencia realizada en Argentina, Brasil, España y Uruguay” (Centro de Estudios sobre Ciencia, Desarrollo y Educación Superior [Redes], 2003). Los tres ejes de estudio que propone son (1) el conocimiento, que busca examinar el nivel de comprensión perceptiva; (2) las actitudes, que comprende la predisposición hacia comportamientos esperados, y (3) los intereses acerca del tema de estudio. Cabe agregar que esta metodología de estudio de percepciones también ha sido adaptada para otros campos de conocimiento, como la gestión de la educación (Ladino, 2015) y al estudio de la cultura de la investigación (Latorre, 2016).

Específicamente, en esta investigación se adaptaron los tres ejes metodológicos al estudio de las percepciones en los estudiantes sobre la tutoría de trabajo de grado, con base además en las categorías halladas en la revisión de investigaciones. A continuación, se definen estos ejes:

- Eje de conocimiento. Trata sobre el conocimiento perceptual e informativo de las categorías generales denominadas: tutoría en el trabajo de grado y rol del tutor.

- Eje de actitudes. Se relaciona, en primer lugar, con la predisposición al cumplimiento del estudiante con la tutoría para realizar el trabajo de grado. En segundo lugar, atañe a la cooperación, la organización, el trabajo en equipo y la motivación, entre otros aspectos que se refieren a la utilización de la tutoría por el estudiante: Los significados, las emociones y los sentidos hacia la tutoría. Finalmente, se refiere a las actitudes y 
comportamientos en la realización de las tutorías, como responsabilidad en el cumplimiento de las tareas, organización del trabajo, colaboración de trabajo en equipo y cooperación.

- $\quad$ Eje de interés. Corresponde a las percepciones del logro, el beneficio y cambio que produce la tutoría para el estudiante en aspectos como: La actualización de conocimientos profesionales desde la tutoría y la autorrealización, el reconocimiento y la satisfacción como estudiante por los avances en la fiabilidad, credibilidad y seguridad en el resultado del trabajo de grado. Además, abarca la autonomía en el aprendizaje y la toma de decisiones en las propuestas, así como los avances en la mejora de la oralidad y la escritura.

Como se señaló más arriba, el otro instrumento que se aplicó fue la entrevista en profundidad a profesores tutores de trabajo de grado sobre "la tutoría" y "la tutoría para el trabajo de grado". Con este propósito se elaboró un guion para homogeneizar los puntos de vista, mantener unos criterios mínimos y lograr discursos articulados. Cabe señalar que es un instrumento estandarizado, abierto y focalizado en las tutorías para el trabajo de grado y las competencias que el tutor debe poseer para desarrollarlas en el estudiante en trabajo de grado. Esta guía, además, está basada en las categorías que se hallaron en la revisión de investigaciones similares, las cuales contienen las mismas preocupaciones acerca del tema investigado. Finalmente se debe agregar que la entrevista en profundidad, como técnica, supone en el caso de este estudio una situación de diálogo y conversación voluntaria de interés del tutor.

Ampliando la perspectiva, se debe mencionar que los investigadores cualitativos estudian la realidad en su contexto natural, tal y como suceden, intentando dar sentido o interpretar los fenómenos de acuerdo con los significados que les dan las personas implicadas. En tal sentido, este estudio trabajó con los datos obtenidos para extraer los significados más relevantes en relación con la tutoría de trabajo de grado, para lo cual los entrevistadores siguieron estos pasos:

- Elaboración de la guía a partir de las categorías halladas en el estudio de antecedentes investigativos.

- Creación de condiciones para realizar la conversación según la guía, de tal manera que no se produjeran interrupciones y hubiese tranquilidad y confianza del entrevistado con el investigador.

- Recolección de la información de manera precisa y fiel a lo expresado por el entrevistado, en formato Word, bajo los siguientes pasos: Escritura del 
documento; lectura y relectura de cada entrevista, para seleccionar los párrafos significativos y marcar las palabras e ideas claves. No se identificó a los entrevistados, sino solo lo expresado.

- Identificación y remarcación con color de los significados de las categorías indagadas en el texto de cada entrevista.

- Elaboración de matriz que sintetizó las entrevistas desde las categorías de análisis.

- Elaboración de tabla que sintetiza las limitaciones pedagógicas y de gestión educativa halladas.

- Análisis e interpretación categorial de las limitaciones pedagógicas y de gestión educativa.

Ahora bien, teniendo claro lo anterior y ya con un contexto referenciado, es de vital importancia conocer las discusiones que se han dado sobre el proceso tutorial, involucrando sus actores y la acción de desarrollar una tutoría.

\section{Polémicas desde la investigación educativa sobre la tutoría, el tutor y el proceso tutorial}

El propósito de este apartado es exponer sintéticamente los diferentes enfoques y las perspectivas teóricas y prácticas que resaltan las investigaciones recientes en Iberoamérica sobre la investigación formativa y las tutorías. En lo que respecta al contexto de este trabajo, se debe resaltar que estos estudios tienen preocupaciones y polémicas actuales muy cercanas al problema de la indagación que se lleva a cabo en la Esmic, lo cual es un indicador de la etapa de desarrollo en que se halla este proceso de cambio pedagógico.

A continuación, se presentan algunos de los autores y los principales resultados de los artículos que se encontraron en la revisión documental. Para comenzar se debe mencionar el trabajo de Durán y Huerta (2008), quienes exponen una experiencia de la tutoría entre iguales con un amplio marco teórico que destaca los siguientes aspectos: La cooperación como una competencia clave; la cooperación como un motor de aprendizaje significativo que se produce de manera colectiva; el aprendizaje cooperativo, que en el contexto universitario adquiere una especial relevancia, puesto que permite utilizar pedagógicamente las diferencias de conocimientos entre los estudiantes y la diversidad dentro del equipo, lo cual es un requisito para establecer relaciones de ayuda mutua y, a la vez, permite prácticas de trabajo autónomo del profesor. Por último, Duran y Huerta (2008) sostienen que 
en el trabajo cooperativo se combina la tutoría y la colaboración, las cuales además cumplen los requisitos del aprendizaje cooperativo.

En segundo lugar, se encuentra el trabajo de Rojas et al. (2009), quienes conciben la tutoría como una herramienta educativa en el proceso formativo de los estudiantes y como una estrategia pedagógica que busca transformar la tradición de que el profesor es el único poseedor del conocimiento. Estos autores aseveran que el papel del profesor se debería dirigir más hacia la organización de la información, así como hacia el diseño y la práctica de estrategias didácticas que permitan una mayor participación, independencia y responsabilidad del estudiante. Así, se destaca no solo que el estudiante debe organizar sus propios espacios, sino que además el profesor tutor tiene una función importante si logra trascender esa actividad simple de repetir información para convertirse en una verdadera guía para el estudiante.

En tercer lugar se pueden mencionar a Venegas y Del Río (2010), quienes reconocen que la tutoría es una actividad inherente a la función del profesor, que se realiza individual y colectivamente con los alumnos de un grupo de clase para facilitar la integración personal de los procesos de aprendizaje.

Por su parte, Pámies y Galindo (2015), proponen cuatro principios que orientan la gestión académica, administrativa y la acción de los tutores y profesores: (1) El alumno es autónomo, (2) los profesores y tutores son provocadores de los aprendizajes, (3) el trabajo es formativo y (4) la institución es facilitadora. Estos principios, más que una declaración de intención, son los criterios que guían la toma de decisiones cotidianas, el diseńo curricular, la definición de didácticas y la organización y gestión del plan de acción tutorial.

Desde otra perspectiva, Coromoto (2009) destaca la tutoría como medio pedagógico para desarrollar el proceso de trabajo de grado, desde la selección del tema que se va a investigar hasta su defensa pública, todo esto en el marco de la investigación universitaria y las responsabilidades de los participantes. Asimismo, el autor describe el proceso de tutoría, desde la selección de alternativas, las cualidades del tutor, su actuación en la difusión de valores y sus incentivos académicos. Coromoto (2009) concluye que el trabajo de grado es un entramado de construcción social y epistémico del conocimiento, microcultural y educativo, que conduce a la formación profesional en investigación, de tal manera que cada estudiante entreteje su propia trayectoria con incertidumbre y con la participación de intereses, creencias, decisiones personales, compromisos y con parámetros definidos, que son, por lo tanto, fundamentales.

Finalmente, Álvarez (2004) ofrece una visión amplia de la tutoría desde el ámbito curricular que la entiende no solo como un proceso de aprendizaje, sino 
también como orientación y entrenamiento profesional respecto a concepciones, conceptos, sistemas y principios que definen un orden para establecer estrategias que incluyan la dimensión pedagógica y la gestión, lo cual puede presentarse como un sistema. Asimismo, señala dos formas de realizar la tutoría: Como método de enseñanza, como forma, metodología de enseñanza, y como una oferta normalizada de enseńanza.

Como se observa, en los debates sobre la tutoría se pueden sintetizar cuestionamientos sobre si es una forma de organización, una estrategia metodológica, un estilo pedagógico del educador, un método, una orientación organizativa del trabajo docente-educativo desde la gestión institucional, un rol del profesor o una nueva manera de entender al maestro en la actualidad, dadas las nuevas facilidades de llegar al conocimiento y de la autonomía del que aprende por el acceso que tiene a este.

Otro aspecto fundamental presente en las diferentes investigaciones revisadas es la preparación de los docentes universitarios para enfrentar la atención tutorial, desde la dimensión pedagógica y la comprensión del nuevo rol que tienen con el conocimiento y el sujeto que aprende. También se hace referencia a su alcance, pues se considera que la nueva tutoría es un proceso de atención a los estudiantes, cuya misión es proporcionarles información, formación y orientación a lo largo de su desarrollo, no solo académico, sino también profesional y personal para su formación integral.

Cabe señalar que esta síntesis es objeto de indagación en la práctica de las tutorías que se realizan para el trabajo de grado en la Esmic, puesto que la institución no cuenta con una declaración en la que se establezca cómo se concibe, su lugar en la formación, su organización ni su prioridad en el currículo, como tampoco en la gestión ni en la vida de la Escuela. Por esta razón, tampoco se refleja en las reglamentaciones estudiantiles y docentes, en los sistemas de calidad ni en los indicadores de evaluación profesoral, lo cual impide que se asuma como una exigencia del estudiante, una responsabilidad del profesor y una garantía de la institución. De ahí la afirmación que se hace en esta investigación de que aún permanecen limitaciones pedagógicas y de gestión educativa para su efectiva realización en los procesos académicos.

Ahora bien, volviendo al análisis de la literatura académica sobre las tutorías, se debe agregar que existen investigaciones con el mismo corte que tiene la que se presenta en este capítulo. Entre estos estudios se pueden citar las siguientes: En primer lugar, el efectuado por Hernández, Jiménez, Guadarrama y Rivera (2016), denominado "La percepción de la motivación y satisfacción de la tutoría recibida 
en estudios de posgrado del Instituto Politécnico Nacional, Unidad Profesional Interdisciplinaria de Ingeniería y Ciencias Sociales y Administrativas (Upiicsa)". Este trabajo estudió la percepción que tienen los egresados de tres programas de maestría con el fin de

identificar los factores que influyen en la satisfacción hacia el trabajo realizado por el director de tesis (tutor) y así identificar posibles áreas de mejoras en beneficio de los posgrados. De esta manera, es posible implementar estrategias que apoyen a los estudiantes para continuar con el trabajo de investigación y elevar sus indicadores de eficiencia terminal y de productividad académica en la tesis de grado de maestría. (Hernández et al., 2016, p. 2)

También se hace referencia a las habilidades que debe poseer el tutor, de modo que pueda orientar acertadamente a los estudiantes en la toma de decisiones adecuadas respecto a su desempeño académico, tales como contar con la capacidad y disposición para escuchar los deseos futuros, metas, aspiraciones y expectativas. Hernández et al. (2016) destacan además que la tutoría no solo coadyuva a la conexión con una persona de experiencia, sino que el apoyo mutuo y las relaciones saludables con los directores de tesis contribuyen positivamente a orientar a los estudiantes de posgrado. De esta forma, la tutoría se considera un proceso sociocognoscitivo creado para transformar a los estudiantes poco experimentados en personas calificadas para resolver problemas incorporándose a redes de investigación en el campo de estudio.

Hernández et al. (2016) agregan que la tutoría es una relación interactiva de intercambio profesional entre individuos con diferentes niveles de experiencia y conocimiento. En este sentido, la función del más experimentado es guiar y asistir al estudiante en formación con el propósito de promover su desarrollo profesional. El tutor necesita, por lo tanto, tener cualidades de liderazgo, conocimiento y destrezas personales que permitan desarrollar un modelo de crecimiento para ambos actores. Así, según estos autores, el papel que debe desempeñar un tutor se resume en tres categorías: (1) Facilitar un ambiente de aprendizaje que satisfaga las necesidades de aprendizaje de cada estudiante, (2) proporcionar retroalimentación positiva y constructiva sobre el progreso del estudiante y su rendimiento, y (3) coadyuvar en el desarrollo intelectual.

En segundo lugar, se puede mencionar la tesis de maestría de Rangel y Jiménez (2016), de la Universidad Simón Rodríguez de Caracas, Venezuela, denominada Un modelo alternativo para aprender a investigar en el posgrado. Vivencias y percepciones de las tutorias de trabajos de grado, estructura de significados en los actores, que desarrolla un enfoque fenomenológico para analizar, a través de entrevistas en 
profundidad, las vivencias y las percepciones de estudiantes y tutores con respecto a la tutoría de investigación. En el documento se enfatiza que los trabajos que discuten los alcances y significados del rol tutorial o que reflexionan críticamente sobre el sentido de su existencia tienen menos desarrollo, entre las cuales incluye las investigaciones sobre las percepciones y las representaciones del rol del tutor.

Cabe agregar que esta investigación toma como punto de partida los desarrollos teóricos y las reflexiones que tienen como base el trabajo de Cepalari (2007). Específicamente, se fundamenta en su visión del rol del tutor en las universidades argentinas como una compleja trama de significados y prácticas que se constituyen y desarrollan en los distintos contextos institucionales para responder a problemáticas específicas.

En la tesis referida se exponen diferentes configuraciones del papel del tutor y los significados que se construyen sobre el fracaso educativo. Entre otras representaciones, Rangel y Jiménez (2016) señalan las siguientes: "El tutor como parte de un dispositivo institucional de tipo remedial para solucionar dificultades situadas en los alumnos"; "el tutor como orientador que brinda respuestas personalizadas a distintas necesidades y problemáticas de los estudiantes", "el tutor como orientador/promotor de aprendizajes académicos en los alumnos" y "el tutor como una forma especial de ser docente" (Rangel \& Jiménez, 2007).

Por su parte, en "Las configuraciones del rol del tutor en la universidad argentina: Aportes para reflexionar acerca de los significados que se construyen sobre el fracaso educativo en la educación superior”, Cepalari (2007) reseña el origen del tutor en la educación y cómo esta función ha tenido un papel clave en relación con los aprendizajes en el marco de los distintos contextos sociohistóricos en los cuales se ha ido configurando su desempeño. Además, destaca como un aspecto importante la relación que tiene la tutoría con las tensiones entre viejas y nuevas formas de concebir el aprendizaje, así como con la enseñanza, la misión y las funciones de la universidad. Por una parte, continúa Cepalari (2007), esta adquiere significado en nuevos escenarios educativos caracterizados por los procesos de convergencia políticos-económicos que se movilizan en distintas regiones del mundo. Por otra parte, la relaciona con los diferentes problemas de la educación superior, tales como: Acceso, deserción, selección por vocación, formación académica y otros de carácter social. Asimismo, resalta el estado de las investigaciones vinculadas al rol del tutor en la agenda actual que proponen sistemas tutoriales en el ámbito institucional de tipo descriptivo o normativo, aunque advierte que son menos prolíferos los avances que analizan y debaten los alcances y significados del rol tutorial o reflexionan críticamente sobre el sentido de su existencia. 
En tercer lugar, el artículo antes mencionado de Martínez, Martínez y Pérez (2016) analiza las percepciones que tienen los estudiantes de la Facultad de Educación de la Universidad de Murcia sobre las fortalezas y las debilidades que asocian a la tutoría, así como sobre las propuestas que plantean para su mejora, para lo cual emplearon como metodología un cuestionario ad hoc denominado "Cuestionario de utilización y satisfacción sobre tutoría universitaria". Los resultados reconocen que, por un lado, la fortaleza más destacada de la tutoría es que favorece la personalización del proceso formativo y, por otro, que la principal debilidad es su escaso desarrollo, de modo que la propuesta de mejora es incrementar las tutorías presenciales.

Martínez, Martínez y Pérez (2016) reconocen que es necesario pasar de la tutoría de asignatura a la tutoría para la carrera, lo cual implica un nuevo papel para el profesorado, un cambio en el enfoque de las actividades educativas y en los métodos, así como centrar la atención en los resultados de aprendizaje. La tutoría se convierte así en un medio para transformar y mejorar la calidad de la enseñanza universitaria, entendida como excelencia docente, al tiempo que debe potenciar el desarrollo integral del estudiante y favorecer la definición del proyecto profesional y de vida. En consecuencia, se trata de una acción orientadora y formativa que colabora en el desarrollo armónico de los aprendices y que facilita la gestión del proyecto, en el cual el tutor es el mediador. Finalmente, los autores argumentan que una conclusión importante del estudio es que la nueva tutoría se replantea y redefine como un proceso de atención a los estudiantes, cuya misión es proporcionarles información, formación y orientación a lo largo de su desarrollo, no solo académico, sino también profesional y personal.

En cuarto lugar, el estudio de Rosas, Fores y Valarino (2006) se refiere a las competencias del tutor de trabajo de grado — desde su desempeño-, según un estudio de las opiniones de estudiantes de posgrado en tesis. En este trabajo se exponen los resultados de una investigación de campo, descriptiva y transversal, realizada con estudiantes que elaboraban sus trabajos de grado o tesis en cinco posgrados de la Universidad Simón Bolívar (Venezuela), los cuales señalan que las diez características más importantes del rol del tutor fueron: (1) Experiencia investigativa, (2) seguridad en sus habilidades, (3) responsabilidad, (4) apertura al abordaje de puntos sometidos a discusión, (5) experiencia para supervisar investigaciones, (6) estabilidad emocional, (7) aporte de ideas y sugerencias constructivas, (8) información actualizada, (9) destrezas en el manejo de información e (10) información sobre líneas de investigación factibles. El estudio, además, diagnosticó el rol del tutor y detectó los elementos más importantes que se deben 
considerar para diseñar, implementar y evaluar programas de asesoría y supervisión de investigaciones.

Otro investigador, Zúñiga (2014), analiza la incidencia que tiene la tutoría en la educación con equidad y respeto a las diferencias individuales. Específicamente, su objetivo fue analizar el Modelo Educativo de Tutoría y Enriquecimiento Extraescolar que vincula profesores-investigadores de instituciones de educación superior con alumnos y alumnas con aptitudes sobresalientes de secundaria en su educación hacia una cultura científica, para lo cual empleó la técnica de grupo focal y la entrevista semiestructurada con el siguiente interrogante: ¿Cuáles son las estrategias de trabajo que emplean los tutores para desarrollar una cultura científica?

Finalmente, Lobato y Arbizu (2005) estudiaron las representaciones sociales de la tutoría universitaria en los profesores y los estudiantes a través de un estudio de caso, en el cual partieron de la premisa de que el aprendizaje y la tutoría es un ambiente cultural y social.

A continuación se sintetizan las problemáticas y las categorías sobre tutorías, tutor y trabajo de grado halladas en la revisión bibliográfica (tabla 1).

Tabla 1. Problemáticas y categorías más tratadas en investigación sobre tutorías

\begin{tabular}{ll}
\hline \multicolumn{1}{c}{ Problemáticas } & \multicolumn{1}{c}{ Categorías extraídas } \\
\hline La autonomía del estudiante, las relaciones & - Trabajo cooperativo \\
interpersonales en la colaboración y el trabajo & - Tutoría entre iguales \\
en equipo que permiten aprender enseńando, & - Aprender haciendo \\
cooperando en las relaciones interpersonales y en & - Investigación formativa como acto cultural \\
equipo & - Enseñanza de la investigación como estrategia \\
& pedagógica \\
& - Trabajo autónomo \\
& - Trabajo en equipo \\
& - Aprendizaje cooperativo como estrategia instruc- \\
& cional que combina tutoría y colaboración \\
La tutoría como una estrategia pedagógica del & - Estrategia pedagógica \\
profesor, una herramienta en el proceso formativo & - Profesor tutor guía del estudiante \\
& - Tutoría como forma de organización \\
& - Tutoría como método de enseńanza \\
El rol del tutor y sus diferentes configuraciones & - "Como parte un dispositivo institucional de tipo \\
& $\begin{array}{l}\text { remedial para solucionar dificultades situadas en } \\
\text { los alumnos" }\end{array}$ \\
& - "Como orientador que brinda respuestas perso- \\
& nalizadas a distintas necesidades y problemáticas \\
de los estudiantes"
\end{tabular}




\begin{tabular}{|c|c|}
\hline Problemáticas & Categorías extraídas \\
\hline El rol del tutor y sus diferentes configuraciones & $\begin{array}{l}\text { - "Como orientador/promotor de aprendizajes } \\
\text { académicos en los alumnos" } \\
\text { - "Como una forma especial de ser docente" }\end{array}$ \\
\hline $\begin{array}{l}\text { Los estilos docentes y la acción tutorial } \\
\text { orientadora }\end{array}$ & - Acción tutorial \\
\hline $\begin{array}{l}\text { La tutoría como herramienta académica del desa- } \\
\text { rrollo de competencias transversales (relación } \\
\text { con el currículo y la gestión educativa: Programa } \\
\text { académico transversal) }\end{array}$ & $\begin{array}{l}\text { - El alumno es autónomo } \\
\text { - Los profesores y tutores son "provocadores de } \\
\text { aprendizaje" } \\
\text { - El trabajo es formativo } \\
\text { - La institución es facilitadora }\end{array}$ \\
\hline Limitaciones o amenazas de éxito de las tutorías & $\begin{array}{l}\text { - Pobreza vocacional } \\
\text { - Falta de motivación para el estudio } \\
\text { - Diferencias culturales } \\
\text { - Dificultades de lenguaje } \\
\text { - Adaptación a la vida académica } \\
\text { - Comunicación oral y escrita } \\
\text { - Trabajo en equipo }\end{array}$ \\
\hline $\begin{array}{l}\text { La relación de la tutoría con la investigación a } \\
\text { través de la enseńanza por proyectos como estra- } \\
\text { tegia para el aprendizaje significativo }\end{array}$ & $\begin{array}{l}\text { - Enseñanza por proyectos } \\
\text { - Aprendizaje significativo }\end{array}$ \\
\hline $\begin{array}{l}\text { El desarrollo de los trabajos de grado, las respon- } \\
\text { sabilidades de los participantes y describir el } \\
\text { proceso de tutoría (asesoría), desde la selección de } \\
\text { alternativas, las cualidades del tutor, su actuación } \\
\text { en la difusión de valores y sus incentivos acadé- } \\
\text { micos. } \\
\text { La tutoría y su relación con la asesoría. }\end{array}$ & $\begin{array}{l}\text { - Tutoría de trabajos de grado } \\
\text { - Trabajo de grado } \\
\text { - Asesoría }\end{array}$ \\
\hline $\begin{array}{l}\text { Tutoría como apoyo a la enseñanza o como forma } \\
\text { de enseñar centrada en la formación profesional }\end{array}$ & $\begin{array}{l}\text { - Tutoría como entrenamiento profesional, como } \\
\text { prácticas tutoriales } \\
\text { - Tutoría como forma de enseñanza (estudiante } \\
\text { organiza su currículo apoyado por un profesor) } \\
\text { - Tutoría como oferta normalizada de enseñanza } \\
\text { para el aprendizaje independiente }\end{array}$ \\
\hline $\begin{array}{l}\text { Tutoría como aclaración de dudas o tutoría para } \\
\text { la formación profesional } \\
\text { Limitaciones en el desarrollo de la tutoría }\end{array}$ & $\begin{array}{l}\text { - Tutoría para la formación integral } \\
\text { - Tutoría presencial } \\
\text { - Percepción sobre la tutoría en estudiantes }\end{array}$ \\
\hline Tutoría como un indicador de calidad educativa & - Calidad educativa \\
\hline $\begin{array}{l}\text { Tutoría en la investigación formativa con refe- } \\
\text { rencia al desarrollo de trabajos de grado }\end{array}$ & - Tutoría en el proceso de investigación formativa \\
\hline
\end{tabular}




\begin{tabular}{|c|c|}
\hline Problemáticas & Categorías extraídas \\
\hline $\begin{array}{l}\text { Percepciones de la tutoría desde la motivación y } \\
\text { la satisfacción }\end{array}$ & $\begin{array}{l}\text { - Seguridad } \\
\text { - Afiliación y afecto } \\
\text { - Reconocimiento } \\
\text { - Logro } \\
\text { - Poder } \\
\text { - Conocimiento } \\
\text { - Autorrealización } \\
\text { - Cambio }\end{array}$ \\
\hline Formas de la tutoría & $\begin{array}{l}\text { - Tutoría presencial } \\
\text { - Tutoría virtual }\end{array}$ \\
\hline $\begin{array}{l}\text { Establece las relaciones de la tutoría del trabajo de } \\
\text { grado con la cultura y educación de la investiga- } \\
\text { ción, más allá del resultado "documento" }\end{array}$ & $\begin{array}{l}\text { - Cultura de la investigación } \\
\text { - Educación científico-tecnológica }\end{array}$ \\
\hline $\begin{array}{l}\text { Las configuraciones de estudiantes y profesores } \\
\text { sobre el rol del tutor }\end{array}$ & $\begin{array}{l}\text { - El tutor como parte de un dispositivo institu- } \\
\text { cional de tipo remedial para solucionar dificul- } \\
\text { tades situadas en los alumnos } \\
\text { - El tutor como orientador que brinda respuestas } \\
\text { personalizadas a distintas necesidades y proble- } \\
\text { máticas de los estudiantes } \\
\text { - El tutor como orientador/promotor de apren- } \\
\text { dizajes académicos en los alumnos } \\
\text { - El tutor como una forma especial de ser docente }\end{array}$ \\
\hline
\end{tabular}

Fuente: Elaborada por los autores.

En la tabla 1 se resumen las problemáticas señaladas por las investigaciones que se analizaron. Este insumo permitió extraer las categorías de análisis para elaborar los instrumentos de investigación (encuesta de percepciones y entrevista en profundidad), con el objetivo de entender el proceso tutorial de la Esmic e identificar las limitaciones pedagógicas y de gestión educativa existentes.

\section{Limitaciones pedagógicas y de gestión educativa acerca de la tutoría de trabajo de grado en profesores tutores y estudiantes: Estudio de caso en la Escuela Militar de Cadetes "General José María Córdova”}

En este apartado se presentan los resultados que se obtuvieron de aplicar la encuesta de percepción sobre las tutorías para el trabajo de grado en una muestra de estudiantes seleccionados de séptimo semestre de Esmic. Dicha encuesta es una de 
las técnicas aplicadas con el propósito de, por un lado, comprender las percepciones de los cadetes a partir de lo que afirman (se dice o se piensa y se actúa) y, por otro, derivar categorías inductivas que informan sobre determinadas limitaciones en el ámbito pedagógico y de la gestión educativa, de tal manera que posteriormente se puedan correlacionar.

Como se mencionó en la primera parte de este capítulo, el cuestionario se aplicó con el propósito de mejorar la investigación formativa del estudiante y futuro oficial del Ejército Nacional de Colombia. Para esto se identificaron las limitaciones pedagógicas y de gestión educativa, así como las ideas que tenían los estudiantes para mejorar dicho proceso académico.

La encuesta constó de cuatro partes. La primera, "Información general", registró las características de las tutorías, tales como asignación del tutor, fase de desarrollo del proceso de investigación, dificultades fundamentales, trabajo en equipo, experiencia en investigación anterior como semilleros, participación en eventos estudiantiles. La segunda, denominada "Las tutorías de trabajo de grado", indagó sobre los ejes que se definieron para el estudio de las percepciones, es decir, conocimiento a nivel de percepción e información; interés desde aspectos como la satisfacción, la fiabilidad y la credibilidad, esta última referida a la utilización de los espacios tutoriales; y la actitud como responsabilidad y participación activa del estudiante. La tercera parte, como aspecto valorativo, se denominó "Debilidades y fortalezas de las tutorías para el trabajo de grado”. Por último, la cuarta consistió en una pregunta abierta sobre las "ideas de propuestas para mejorar las tutorías para el trabajo de grado", cuya finalidad era que los estudiantes reflexionaran sobre las fortalezas y las debilidades de la tutoría, además de que propusieran ideas de mejora como parte de la comunidad académica y de su responsabilidad como estudiantes.

\section{Una caracterización de los hallazgos}

A continuación, se presentan de manera sintética los principales resultados.

- Se observó la poca participación del estudiante en la selección de su tutor, que es fundamentalmente un proceso por asignación. Además, esta interacción se limita a aspectos organizativos y no pedagógicos.

- Según los datos aportados por los estudiantes, las tutorías inician entre el quinto y, principalmente, sexto semestre, un nivel que resulta tardío si se tienen en cuenta las características de la formación militar y su incidencia en los tiempos de elaboración del trabajo de grado. (A manera de 
aclaración se aclara que el proceso de formación en la Esmic es de ocho semestres).

- Se encontró que no hay regularidad ni equilibrio en la realización de las tutorías. Al respecto, llama la atención que el 41,67 \% de los estudiantes son atendidos cada 15 días, por lo cual se considera racional el tiempo para llevar el seguimiento necesario, así como la orientación que requiere el estudiante. Por su parte, el 13,56\% de los encuestados señala que es atendido dos o tres veces en el semestre, lo que significa abandono del seguimiento necesario por el profesor e incumplimiento y despreocupación del estudiante.

- Teniendo en cuenta que los estudiantes encuestados cursaban el séptimo semestre y debían presentar resultados en la presustentación de trabajo de grado en dicho periodo académico, resultan preocupantes los datos expuestos, pues respecto a los avances alcanzados que se revelaron en este estudio, el 33,33 \% estaba en elaboración de los marcos de referencia, el $13,89 \%$ en la aplicación de instrumentos y, peor aún, el 11,44\% hasta ahora iniciaba el planteamiento del problema. Por lo tanto, solo el 16,67 $\%$ tenían resultados y estaban elaborando su informe, lo cual evidencia retraso en el proceso de investigación para el trabajo de grado.

- Respecto a las formas de la tutoría se debe resaltar como positivo que el $79,41 \%$ de los cadetes reconocieron que es fundamentalmente que esta sea presencial, Sin embargo, es contradictorio que no se hace referencia a la virtualidad, lo cual significaría que el profesor y el estudiante no se comunican antes de la presencialidad, con los avances, para dialogar sobre ellos.

\section{Respecto a las percepciones sobre las tutorías de trabajo de grado}

En este apartado se presentan los hallazgos respecto a las percepciones de los estudiantes sobre las tutorías de trabajo de grado.

\section{EN LOS ESTUDIANTES}

Como parte del cuestionario se les pidió a los estudiantes que seleccionaran tres sentimientos que les causara realizar el trabajo de grado. Así, se encontró que los sentimientos más destacados por los estudiantes son congruentes con la motivación que expresan tener para hacer el trabajo de grado y, con el buen desarrollo del proceso de aprendizaje e investigación, tales como: el interés (75\%), la responsabilidad $(75 \%)$ y la curiosidad y el temor representados por un 30,55\%, siguiéndole 
la seguridad, la cooperación y colaboración con $25 \%$. Todos conformes a una actitud positiva hacia las tutorías y el trabajo de grado, puesto que derribar las barreras del temor es parte de la labor pedagógica del tutor.

También se observó que los porcentajes más bajos corresponden a sentimientos como rechazo, ignorancia y desinterés, lo cual significa que, en general, los estudiantes se sienten listos para avanzar en su proceso formativo. Asimismo, al señalar las cinco palabras que más se relacionan con la investigación para el trabajo de grado, se evidenciaron algunos aspectos contradictorios: por un lado, reconocen que la observación $(69,44 \%)$, los métodos y las metodologías $(61,11$ $\%$ ) y la bibliografía (50 \%) son necesarios en su trabajo de grado, además de que señalan que estos deben estar acompañados de actitudes como la responsabilidad $(61,11 \%)$ y la innovación $(50 \%)$, seguidos del liderazgo y creatividad (36,11\%), el equipo de investigación $(41,66)$ y la motivación $(38,88 \%)$. Sin embargo, por otro lado, son bajos los reconocimientos que se hacen al factor humano como la colaboración (2,77\%), el tutor temático (11,11\%) y el trabajo en equipo ( $0 \%)$.

Asimismo, otro aspecto negativo que arroja el cuestionario es que los cadetes no mencionaron el conocimiento teórico $(0 \%)$, cuestión que refleja algunas de las limitaciones que actualmente tiene la calidad científica de los trabajos de grado, así como su comprensión de la ciencia y la cultura de la investigación, que no relacionan con la bibliografía.

Además, las respuestas que dieron los estudiantes respecto a lo que entendían como tutoría para su trabajo de grado - a través de puntajes de cero a tres y siendo tres el de más valor- indican que reconocen como tutoría fundamentalmente lo siguiente: una asesoría $(72,22 \%)$, una forma de enseñanza $(69,44 \%)$, una forma de organización de la investigación $(66,66 \%)$, un entrenamiento profesional $(63,88 \%)$, aprendizaje cooperativo $(61,11 \%)$, un método de enseńanza $(50 \%)$, así como reconocen a la tutoría como una estrategia pedagógica y una enseñanza por proyecto con un mismo puntaje de $47,22 \%$. Al analizar estos datos se advierte que los cadetes reconocen que la tutoría para el trabajo de grado es conexa con la enseñanza y el aprendizaje, con procesos pedagógicos y educativos, los cuales les permiten desarrollar las competencias de investigación necesarias para el trabajo de grado. En este sentido, los estudiantes tienen claridad de qué necesitan de un tutor temático, cuestión que se reconoce en los debates actuales sobre el tema.

Ahora bien, la percepción que tienen los cadetes sobre lo que es un tutor(a) de trabajo de grado, en orden de puntuación según están totalmente de acuerdo y de acuerdo, son: Un profesor guía (94,43\%), un orientador que brinda respuestas personalizadas $(91,66 \%)$, un promotor de aprendizajes académicos 
en los alumnos $(86,1 \%)$, un provocador de aprendizajes $(88,88 \%)$, un asesor (75\%), un investigador $(72,21 \%)$ y una nueva forma de ser docente $(58,32$ $\%)$. Se debe agregar que en las respuestas a estas categorías, que se debaten en las investigaciones actuales, los estudiantes perciben que el tutor es un guía, un orientador, un promotor o un provocador de aprendizajes, de manera que no es tan reconocido como asesor-investigador.

En este sentido, con el propósito de conocer la percepción que tienen los estudiantes sobre sus actitudes ante el trabajo de grado y las tutorías, se les pidió que marcaran "sí", "no" o "indeciso" acerca de las siguientes categorías - los porcentajes corresponden a las respuestas afirmativas-: Coopero con responsabilidad en el cumplimiento de las tareas de investigación (88,88 \%), lidero y oriento a mi equipo en las tareas asignadas por el tutor $(88,88 \%)$, presento las tareas de investigación en forma pulcra, ordenada y completamente terminadas $(86,11 \%)$ y asisto a todas las tutorías (75\%). Estas cifras evidencian que los cadetes tienen una percepción muy positiva del cumplimiento de sus responsabilidades, lo cual resulta preocupante si se tienen en cuenta las limitaciones que aún existen en los trabajos de grado.

En cuanto a los resultados a la afirmación de si las tutorías los actualizan en los conocimientos profesionales, estos se centran en la categoría de "siempre", con el $86,11 \%$ del total, lo que evidencia de alguna manera que reconocen su importancia. Sobre si tienen gusto por asistir a las tutorías para el trabajo de grado, el $88,88 \%$ de los encuestados respondió que "siempre", lo cual se puede deber a que a través de las tutorías evidencian un nivel de avance en su investigación. En relación con si sienten seguridad en el conocimiento y el resultado de la investigación que realizan para el trabajo de grado, el 86,1 \% respondió que "siempre". Y finalmente, el 86,11\% respondió que "siempre" a la pregunta de si sienten la diferencia entre las clases y las tutorías, lo cual puede ser el reflejo de mayor autonomía en el aprendizaje y en la toma de decisiones. A continuación, en la tabla 2, se presenta un resumen de las percepciones e imágenes que tienen los estudiantes encuestados según los ejes de conocimiento, las actitudes y los intereses en la tutoría de trabajo de grado.

Con base en este análisis es posible proponer los siguientes aspectos para mejorar el desarrollo de las tutorías de trabajos de grado: Disponer de tiempo y apoyo para realizar buenos trabajos de grado; asignar un horario adecuado; verificar la asistencia de los tutores y estudiantes a reuniones periódicas; desarrollar las asesorías con el material de investigación y, por último, el proyecto tiene que ser orientado a las necesidades particulares de la formación profesional. 
Tabla 2. Resumen de las percepciones e imágenes de los estudiantes encuestados según los ejes de conocimiento, actitudes e interés en la tutoría de trabajo de grado

\begin{tabular}{|c|c|c|}
\hline Sentimiento & Conocimiento & Actitud \\
\hline $\begin{array}{l}\text { Valoración y significado de las } \\
\text { tutorías: actualización; seguridad } \\
\text { por los avances en el conoci- } \\
\text { miento y la investigación; mayor } \\
\text { autonomía en el aprendizaje y en } \\
\text { la toma de decisiones. }\end{array}$ & $\begin{array}{l}\text { Cinco palabras relacionadas con } \\
\text { el trabajo de grado: observa- } \\
\text { ción, metodologías, bibliografía, } \\
\text { responsabilidad e innovación. Con } \\
\text { bajo puntaje: colaboración, tutor } \\
\text { temático y conocimiento teórico. } \\
\text { La tutoría es: asesoría, forma de } \\
\text { enseñanza, forma de organiza- } \\
\text { ción de la investigación, entrena- } \\
\text { miento profesional, aprendizaje } \\
\text { cooperativo. } \\
\text { El tutor de trabajo de grado } \\
\text { es: profesor guía, orientador, } \\
\text { promotor, provocador de aprendi- } \\
\text { zajes, no es así asesor e investigador. }\end{array}$ & $\begin{array}{l}\text { Actitudes ante el trabajo de } \\
\text { grado y las tutorías }(88 \%) \text { : } \\
\text { - "Coopero con responsabilidad } \\
\text { en el cumplimiento de las } \\
\text { tareas de investigación". } \\
\text { - Lidero y oriento a mi equipo } \\
\text { en las tareas asignadas por el } \\
\text { tutor". } \\
\text { - "Presento las tareas de inves- } \\
\text { tigación en forma pulcra, } \\
\text { ordenadas y completamente } \\
\text { terminadas. }\end{array}$ \\
\hline
\end{tabular}

Fuente: Elaborada por los autores.

\section{EN LOS TUTORES}

En cuanto a la entrevista en profundidad a tutores de trabajo de grado de estudiantes encuestados de séptimo semestre, es necesario señalar que se realizaron las siguientes preguntas: ¿Qué entiende por tutoría? Para usted, ¿qué es un tutor de trabajo de grado? ¿Cómo desarrolla la tutoría de trabajo de grado con sus estudiantes? Para usted, ¿la tutoría es: asesoría, consultoría, estrategia pedagógica, forma y método de enseñanza o un nuevo rol de ser profesor en la universidad? ¿Qué competencias se deben lograr en el estudiante a través de la tutoría de trabajo de grado? Los resultados de esta sección se presentan a continuación:

- Se encontró una dispersión en la comprensión perceptiva sobre lo que es una tutoría, lo cual genera una pobre conceptualización sobre esta. Algunos tutores la identifican con asesoría, otros con una guía y otros simplemente como parte de la labor docente. Otros reconocen la importancia de la articulación entre los aspectos metodológicos y los temáticos, de manera que identifican que un tutor debe tener las dos competencias para poder hacer eficaz el acompañamiento al estudiante.

- Quienes integran la asesoría o la consultoría a la tutoría (se señala la asesoría y la consultoría sin definirlas ni diferenciarlas), las reconocen como la forma en que se ofrece conocimiento de expertos en el ámbito 
disciplinar, los cuales son de utilidad. Sin embargo, expresan que el trabajo recae luego sobre el tutor, quien debe integran estos conceptos con estrategia pedagógica para desarrollar el trabajo de grado.

- En cuanto al rol de tutor de trabajo de grado, se encuentra que hay confusión y conflicto entre el campo disciplinar y el metodológico. Del mismo modo sucede con la concepción de tutor como orientador y mediador, o responsable del trabajo de grado, lo cual significa que es necesario establecer con claridad las tareas, responsabilidades y relaciones de los estudiantes y del tutor, la institución y el estudiante. También se halló que no existe preparación pedagógica sobre la investigación formativa, de tal modo que permita desarrollar tutorías de calidad.

- En los resultados se destacan las diferentes maneras en que se desarrolla el trabajo de grado, lo cual tiene estrecha relación con las comprensiones sobre la tutoría y la acción tutorial del profesor. Otro aspecto es la manera en que se produce el acercamiento tutorial, es decir, la asignación de trabajos de grado a un docente por idoneidad o la escogencia del tutor por parte de los estudiantes por cercanía, admiración o empatía temática.

- Respecto a la presencialidad del tutor, se reconoce que es necesario promoverla como tendencia pedagógica a través de formas y métodos de enseñanza. Sin embargo, los entrevistados expresan que posteriormente la abandonan debido a las dificultades organizativas de tiempos de dedicación, tanto de los estudiantes como de los profesores tutores, aspecto en el que intervienen disímiles factores ajenos a la formación. Asimismo, no se aprovecha pedagógicamente las posibilidades que ofrece la tecnología para realizar encuentros virtuales, sino que se recurre a esta herramienta solo como alternativa de comunicación, control y revisión del trabajo, de tal manera que se pierde el trabajo en equipo y el diálogo entre el profesor y el estudiante, entre otros.

- Se observó que solamente un profesor se refirió a la necesidad de elaborar un plan de trabajo tutorial.

- Algunos docentes identificaron la tutoría con la idea de estrategia pedagógica, lo cual significa que pone en práctica aspectos pedagógicos del aprendizaje significativo, de motivación y de la acción docente para facilitar el proceso en general. Sin embargo, no hay referencias al modelo pedagógico de la institución y mucho menos a las competencias que se deben formar. En este sentido, no se destacan diferencias entre las 
estrategias pedagógicas de enseñanza y aprendizaje, ni se mencionan los nuevos modelos ni las didácticas para trabajar la tutoría en las condiciones propias de la Esmic.

- Es importante resaltar que pocos entrevistados entienden la tutoría y la acción tutorial como una nueva modalidad y rol del profesor: Investigador que intercambia y dialoga con el estudiante, que crea un ambiente de aprendizaje que le da la posibilidad de que sea autónomo en su aprendizaje. Profesor que está obligado a construir nuevos caminos pedagógicos, metodológicos y didácticos para un aprendizaje colaborativo y por proyectos.

- Solo un profesor utilizó la autocrítica para señalar que "no se sabe desarrollar tutorías", mientras que el resto considera que las limitaciones están fuera de su acción tutorial y que corresponden a la dimensión administrativa y en el estudiante.

Finalmente, los tutores identificaron las siguientes limitaciones en el proceso tutorial, que se pueden agrupar en tres ítems: (1) Frente a los estudiantes, (2) en la labor tutorial y (3) la función administrativa:

- En cuanto a los estudiantes, se encontró que tienen falta de interés y compromiso; bajo nivel de conocimiento y de cultural general; dificultades en la redacción y en la extracción de información; falta de capacidad de análisis que conduce al plagio y a no analizar y construir ideas propias; poca autonomía, escaso pensamiento crítico y no ha formación de opinión; deficiencias en el tiempo que dedican al trabajo de grado; pobre cultura de investigación, pues los estudiantes no priorizan el proceso de investigación para el trabajo de grado; irresponsabilidad en cuanto a la búsqueda de información y cumplimiento de las tareas.

- En la labor tutorial se detectó pobre espacios de diálogo por parte del profesor con sus estudiantes, lo cual limita la confianza necesaria para trabajar juntos.

- $\quad$ Respecto a la función administrativa, la información analizada muestra que se carece de una organización del estado del arte de los anteriores trabajos de grado; falta de garantías para el efectivo desarrollo de una tutoría, en razón a que se presentan actividades para los estudiantes que afectan su cumplimiento con las horas pactadas para estas labores; es necesario mayor precisión en el modelo pedagógico, sobre la cultura 
militar respecto a la investigación, así como del rol del tutor en el contexto de la Esmic; poca asignación horaria al tutor para desarrollar las tutoría de trabajos de grado. Por último, se encontró que hay grupos de tres estudiantes en trabajo de grado, lo cual conduce, en ocasiones, a inadecuadas relaciones de trabajo en equipo.

A manera de síntesis, las tablas 3 y 4 reflejan las limitaciones que se encontraron en el ámbito pedagógico y la gestión educativa. La información que presentan es resultado de las percepciones que manifestaron los estudiantes encuestados y los tutores entrevistados sobre las tres categorías investigadas: Tutoría, tutor y proceso de tutoría. El propósito de esta síntesis es facilitar el análisis y la comparación, así como relacionar las limitaciones detectadas e identificar categorías pedagógicas y de gestión educativa que permitan señalar las principales problemáticas a solucionar en la Esmic. Así mismo, contrastarlas con los resultados de la primera etapa de investigación, que analizó la formación de competencias de investigación desde la enseñanza y el aprendizaje de metodología de la investigación.

Tabla 3. Matriz de síntesis de las limitaciones pedagógicas identificadas en el estudio

\begin{tabular}{lc}
\hline \multicolumn{1}{c}{ Desde el ámbito pedagógico } \\
\hline Categorías de análisis & Limitaciones señaladas por los tutores \\
Tutoría & Dispersión de su comprensión de la práctica pedagógica, experiencial y no de carácter teórico, \\
tampoco desde el modelo pedagógico. \\
- No se diferencia con claridad y se utiliza indistintamente los términos acompañamiento, asesoría, consul- \\
toría, guía, orientación o labor docente. Esto evidencia falta de claridad, lo cual dificultal los entendimientos \\
y el diálogo académico, así como las acciones comunes para su mejoramiento. \\
- Se realiza indistintamente con base en la experiencia y el conocimiento que tiene el tutor de otras \\
universidades, lo cual genera que la actividad no se adecúe a las particularidades del contexto de \\
formación. \\
Limitaciones señaladas por los estudiantes \\
- La tutoría para el trabajo de grado es conexa a la enseñanza y el aprendizaje, con procesos pedagó- \\
gicos y educativos, que le permiten desarrollar las competencias de investigación necesarias para \\
el trabajo de grado. \\
- No hay una regularidad ni equilibrio en la realización de las tutorías que exija la sistematicidad en el \\
seguimiento de las tareas del estudiante. Sin embargo, los estudiantes tienen claro lo que necesitan \\
de un tutor temático. \\
- En coherencia con la comprensión de la tutoría, destacan que el tutor es un guía, un orientador, un \\
promotor, un provocador de aprendizajes. No obstante, no es tan reconocido como asesor-investigador. \\
Categorías extraídas de las limitaciones existentes \\
Conocimientopedagógico: Sobre tutoría, tutor, competencias de investigación, investigación formativa, \\
estrategias pedagógicas de educación científica, investigación formativa, modelo pedagógico no \\
tratado como fundamento de partida.
\end{tabular}




\section{Desde el ámbito pedagógico}

Categorías de análisis Tutoría

\section{Categorías de análisis}

Tutor: Se refiere a la comprensión o imagen desde el conocimiento perceptivo que se tiene de este sujeto pedagógico.
Comunidad académica: Diálogo entre colegas teórico y pedagógico desde el contexto de formación; entre profesor y estudiante en los procesos de aula; en la tutoría a través de diferentes técnicas didácticas. Sistematización y organización de los problemas de investigación, de los enfoques teóricos y la investigación de carácter muy formal.

\section{Limitaciones señaladas por los tutores}

- Falta concientizar a los estudiantes sobre lo que es y significa un trabajo de grado.

- Pobre referencia al modelo pedagógico y las competencias de investigación que se deben formar para ser tutor, pues no es claro el rol de profesor tutor y, por lo tanto, hace falta trabajar en su construcción: Funciones, responsabilidades, competencias por desarrollar.

- No se mencionan estrategias pedagógicas de enseñanza y aprendizaje, ni los nuevos modelos y técnicas para la investigación formativa.

- No hay autocrítica, de manera que los problemas se sitúan fuera de la acción tutorial, específicamente en el ámbito administrativo y en los estudiantes.

- Dispersión de significados sobre el conocimiento y las actitudes para ser tutor de trabajo de grado, en cuanto a ser orientador, mediador y responsable del trabajo de grado. Esto significa que es necesario establecer claramente su rol académico.

- No existe preparación pedagógica sobre la investigación formativa y se desconoce el proceso que se desarrolla en la Esmic.

- Pobre diálogo del profesor con sus estudiantes, lo cual impide que se cree la confianza necesaria para trabajar juntos. Esta situación se origina desde el aula, de manera que se limita las relaciones de los estudiantes con sus tutores.

- Falta de capacidad de diálogo y flexibilidad para realizar debates teóricos y pedagógicos entre los profesores para solucionar los problemas de la formación de los estudiantes.

- No es claro el rol de profesor tutor en la Esmic. En este sentido, falta construir institucionalmente la figura del tutor para saber cómo es su deber ser. Asimismo, es importante resaltar que el modelo pedagógico está en el discurso, desde donde se debe pensar las funciones de un tutor en el ámbito pedagógico y demás espacios educativos.

- Falta de interés, compromiso y responsabilidad en los estudiantes, lo cual desmotiva al tutor.

- Es necesario que haya mayor claridad en el modelo pedagógico y la cultura militar respecto a la investigación, los aspectos epistemológicos y los objetos de estudio, tanto en cuanto a la teoría como en la práctica, no solo en lo formal.

- Existe un conflicto entre el ámbito disciplinary el metodológico, pues se afirma que un solo tutor debería asumirlas, 10 cual pone en evidencia el desconocimiento sobre sus diferencias e importancia independiente.

- Falencias en diferenciar y manejar el aspecto metodológico general y particular, de ahí la necesidad de que se cuente con experiencia en un campo del conocimiento y en la investigación.

- No existe preparación pedagógica sobre la investigación formativa.

Limitaciones señaladas por los estudiantes

- No hay una regularidad ni equilibrio en la realización de las tutorías que exija la sistematicidad en el seguimiento de las tareas del estudiante. Sin embargo, los estudiantes tienen claro lo que necesitan de un tutor temático.

- En coherencia con la comprensión de la tutoría, destacan que el tutor es un guía, un orientador, un promotor, un provocador de aprendizajes. No obstante, no es tan reconocido como asesor-investigador.

\section{Categorías extraídas de las limitaciones existentes}

- Didáctica: Conocimiento que debe emplear el tutor para desarrollar un efectivo proceso de asesoría con sus estudiantes.

- Relación tutor-tutorado: Roles de los tutores y los estudiantes, responsabilidades, actitudes y comportamientos, relaciones, diálogo, confianza, seguridad, entre otros. 


\section{Desde el ámbito pedagógico}

\begin{tabular}{lc}
\hline Categorías de análisis & Categorías extraídas de las limitaciones existentes \\
$\begin{array}{l}\text { Tutor: Se refiere a la } \\
\text { comprensión o imagen desde }\end{array}$ & $\begin{array}{l}\text { Conocimiento de la profesión: Sobre las ciencias militares, los problemas profesionales, y las parti- } \\
\text { culnvestigación en los aspectos epistémicos y metodológicos del objeto de estudio }\end{array}$ \\
$\begin{array}{l}\text { el conocimiento perceptivo } \\
\text { que se tiene de este sujeto }\end{array}$ & $\begin{array}{c}\text { - Cultura de la investigación: Relación entre el ámbito disciplinar y metodológico, entre el campo } \\
\text { pedagógico. }\end{array}$ \\
$\begin{array}{l}\text { metodológico general y el particular, articulado con el diseño y ejecución. Capacidad de análisis } \\
\text { para la elaborar documentos escritos. }\end{array}$
\end{tabular}

\section{Categorías de análisis}

Proceso de Tutoria: Referida a la comprensión o imagen desde el conocimiento perceptivo que se tiene de esta actividad pedagógica.

\section{Limitaciones señaladas por los tutores}

- Bajo nivel del conocimiento y cultura general de los estudiantes.

- Dificultades en la redacción de párrafos y en la extracción de información e ideas.

- Falta de capacidad de análisis de las temáticas, razón por la cual los estudiantes copian y no analizan.

- No tienen una idea de trabajo de grado o un anteproyecto cuando llegan donde el tutor.

- No se sienten responsables del trabajo de grado, lo cual representa una tarea muy desgastante para el tutor. Por tal razón, el tutor termina haciendo el trabajo de grado, no solo corrigiendo.

- No se destacan diferencias entre las estrategias pedagógicas de enseñanza y aprendizaje, no se mencionan los nuevos modelos, las técnicas ni menos aún se habla de competencias.

- Abandono de la presencialidad en las tutorías. Aunque el proceso inicia con esta presencialidad, progresivamente se abandona debido a dificultades organizativas, especificamente por los tiempos de los estudiantes y los profesores. Cabe señalar que en esta problemática intervienen disímiles factores ajenos a la formación: Contratación, prioridades, voluntades. Por lo tanto, los encuentros virtuales se convierten en una alternativa de comunicación, control y revisión del trabajo, pero se abandona el trabajo en equipo, el diálogo entre profesor y estudiante, entre otros aspectos.

- No se diferencia el ámbito metodológico general del particular, de ahíque sea necesario que se tenga experiencia en un campo del conocimiento.

- Poco conocimiento metodológico del estudiante cuando inicia el proceso con el asesor temático (tutor temático).

- Dificultades en el papel del lector o jurado, que debe ser más constructivo en el proceso de presustentación a sustentación.

- No existe diálogo académico, pues los profesores son de hora cátedra y las pocas reuniones que se hacen en las facultades tratan sobre todo de aspectos técnicos, de las formas, y no alrededor de las teorías, los autores, los enfoques, etc., del conocimiento profesional.

- Carencia real de comunidad académica para que esta permee todo el currículo y que sea posible identificar desde los enfoques los problemas de investigación, los autores que se deben trabajar, las herramientas teóricas ymetodológicas.

- Limitaciones para entender y analizar los aspectos teóricos y epistemológicos de la labor pedagógica, así como los técnicos: Guías y formatos.

\section{Limitaciones señaladas por los estudiantes}

- Poca participación del estudiante en la selección de su tutor. Esta se hace fundamentalmente por asignación, de tal manera que se limita a aspectos organizativos y no pedagógicos.

- No hay una regularidad ni equilibrio en la realización de las tutorías que exija la sistematicidad en el seguimiento de las tareas del estudiante.

- Existe retraso en el proceso de investigación para el trabajo de grado en el séptimo semestre, momento en el cual se debe estar presustentando los resultados.

- Falta de complementariedad entre las formas de tutoría presencial y virtual, de tal manera que se adecúe a las posibilidades de tiempo de estudio de los estudiantes de la Esmic. 


\section{Desde el ámbito pedagógico}

\begin{tabular}{|c|c|}
\hline $\begin{array}{l}\text { Lategorías de análisis } \\
\text { roceso de Tutoría: Referida } \\
\text { la comprensión o imagen } \\
\text { lesde el conocimiento } \\
\text { erceptivo que se tiene de } \\
\text { sta actividad pedagógica. }\end{array}$ & $\begin{array}{l}\text { - Es casi nulo el reconocimiento que se hace del factor humano en la elaboración del trabajo de grado en } \\
\text { aspectos como la colaboración, el tutor temático, el trabajo en equipo, así como al conocimiento teórico, } \\
\text { cuestión que se expresa en la calidad científica de los trabajos de grado. } \\
\text { - Falta de objetividad del estudiante para describir y valorar sus sentimientos y actitudes en el desarrollo del } \\
\text { trabajo de grado, pues sus percepciones indican, entre otros aspectos: Responsabilidad, curiosidad e interés, } \\
\text { no así el rechazo, la ignorancia. } \\
\text { - Preocupa la imagen positiva que tienen sobre el cumplimiento de sus responsabilidades en las tutorías para } \\
\text { el trabajo de grado en cuanto a la cooperación, el liderazgo, el trabajo en equipo y el riguroso cumplimiento } \\
\text { de las tareas, ya que no se manifiesta en los resultados. } \\
\text { - Falta de tiempo y de estrategias para organizarlo, poca colaboración del trabajo o de interés e irresponsabi- } \\
\text { lidad en el uso del tiempo para estudiar e investigar. } \\
\text { - Desinterés en responder a la pregunta sobre las fortalezas y las debilidades de la tutoría del trabajo de grado } \\
\text { (40\%). Esto muestra ignorancia o falta de compromiso para pensar las posibles debilidades que se deben } \\
\text { resolver en la tutoría de trabajo de grado en la institución. }\end{array}$ \\
\hline
\end{tabular}

\section{Categorías extraídas de las limitaciones existentes}

Trabajo en equipo: Capacidad de tener una comunicación asertiva, unos roles definidos y un compromiso con el desarrollo del trabajo de grado.

Comunicación asertiva: Diálogo claro, preciso y respetuoso entre los participantes del proceso de trabajo de grado, en el cual la actitud es el valor que permite transmitir la información.

Condiciones de trabajo: Claridad en el proceso de trabajo de grado a fin de establecer y facilitar los espacios y elementos para desarrollarlo, de modo que conduzca a un producto de calidad.

Coordinación y seguimiento: Desarrollo de actividades que permitan verificar de manera continua el proceso de elaboración de los trabajos de grado. Selección de tutor, iniciación del proceso de trabajo de grado.

Crítica y autocritica: Objetividad, corresponsabilidad, proceso integrado por diferentes actores, jurados, coordinadores, tutor, equipo de estudiantes, entre otros.

Complementariedad de las formas de tutoría: Relación entre la presencialidad y la virtualidad, trabajo colectivo e individual.

Fuente: Elaborada por los autores.

Tabla 4. Matriz de síntesis de limitaciones de gestión educativa identificadas en el estudio

Desde la gestión educativa

\section{Categorías de análisis Limitaciones señaladas desde los tutores \\ Tutoría \\ - Falta de claridad en las tareas, responsabilidades y relaciones de los estudiantes, el tutory la institución. \\ Limitaciones señaladas desde los estudiantes \\ - Poca participación del estudiante en la selección de su tutor. Este proceso se hace fundamental- mente por asignación, de manera que se limita a aspectos organizativos y no pedagógicos.}

\section{Categorías extraídas de las limitaciones existentes}

Sistema de investigación formativa: Conjunto de procesos y acciones que conducen a desarrollar la investigación formativa y el trabajo de grado en la Esmic, respecto a estructuras de funcionamiento, roles y relaciones académicas.

Coordinación y seguimiento: Desarrollo de actividades que permitan verificar el proceso de seguimiento en la elaboración de los trabajos de grado en todos los actores. 


\section{Desde la gestión educativa}

\begin{tabular}{ll}
\hline Categorías de análisis & Limitaciones señaladas desde los tutores \\
Tutor & - No hay debate ni preparación pedagógica a los tutores. Se supone que se sabe ser tutor y que por eso \\
no es necesario capacitarlos ni alinearlos, lo cual también trae falta de motivación. \\
- Falta de credibilidad en el proceso de construcción del trabajo de grado. Hay desmotivación del \\
tutor, pues los estudiantes con malos trabajos de grado se gradúan y, lo peor, mandan a hacer los \\
trabajos de grado. \\
- Falta de tiempo y espacios de los tutores, pues trabajan en otras instituciones por asuntos de \\
contrato y necesidades económicas de los docentes. \\
- Es una falencia nombrar al tutor solo por lo temático-disciplinar, por la carga académica o por la \\
contratación.
\end{tabular}

\section{Categorías extraídas de las limitaciones existentes}

Claridad sobre investigación formativa: Información veraz y suficiente para entender el alcance del desarrollo de un trabajo de grado aplicando los medios técnicos e instrumentos que se requieran según el problema, en el marco de las líneas de investigación de la Esmic.

Categorías de análisis Proceso de tutoría de trabajo de grado

\section{Limitaciones señaladas desde los tutores}

- No existe una base de datos de consulta sobre el estado del arte de los anteriores trabajos de grado presentados a los programas, lo cual impide darles continuidad algunos y tener una orientación sobre las líneas de investigación.

- Restricciones de salidas que requieren de procesos de autorización previos para la búsqueda de información y eventos, entre otros.

- Los cadetes tienen limitado espacio para investigar en cuanto a visitas a otras universidades e instituciones de prácticas militares y civiles, por lo cual se requiere de mayor autonomía.

- Restringir el grupo de trabajo de grado hasta máximo, dos estudiantes.

- Pobre incidencia de la investigación formativa y el trabajo de grado en la evaluación del estudiante, solo es un requisito.

- Escaso tiempo en el comienzo de la asignación del tutor y el inicio de las tutorías para trabajo de grado, pues el tiempo en el séptimo semestre es corto por la cantidad de salidas y las tareas que interrumpen los proceso.

- Limitadas estrategias educativas para crear conciencia sobre la importancia de la investigación desde los primeros semestres, sobre todo en las ciencias militares, para que los estudiantes desarrollen motivaciones e intereses a través de la búsqueda bibliográfica y una orientación clara en los problemas que se deben solucionar.

- Imprecisión entre las opciones de grado y el trabajo de grado, necesidad de estudiar sus diferencias y flexibilizar las modalidades de trabajo de grado como resultado.

- Carencia de reglas claras de los roles en el proceso de tutoría de trabajo de grado, sobre el tutory el tutorado.

- Inexistencia de pautas pedagógicas acordes con el modelo pedagógico de la Esmic y que sean construidas desde la experiencia de profesores tutores con resultados.

\section{Limitaciones señaladas desde los estudiantes}

- Desinterés en responder a la pregunta sobre fortalezas y debilidades de la tutoría del trabajo de grado (40\%), lo cual muestra ignorancia o falta de compromiso para pensar las posibles debilidades que se deben resolver en la tutoría de trabajo de grado en la institución como parte de la comunidad académica y actor fundamental del proceso.

- Carencia de tiempo y falta de estrategias para organizarlo, poca colaboración del trabajo o de interés y responsabilidad en el uso del tiempo para estudiar e investigar. 


\section{Desde la gestión educativa}

\begin{tabular}{ll}
\hline Categorías de análisis & Limitaciones señaladas desde los estudiantes \\
Proceso de tutoría de & - Tardía iniciación de las tutorías de trabajo de grado, fundamentalmente en séptimo semestre. \\
trabajo de grado & - Poca participación del estudiante en la selección de su tutor. Este proceso se hace fundamental- \\
mente por asignación, de manera que se limita a aspectos organizativos y no pedagógicos. \\
- No hay regularidad ni equilibrio en la realización de las tutorías que exija sistematicidad en el \\
seguimiento de las tareas del estudiante. \\
Categorías extraídas de las limitaciones existentes \\
Actitud y motivación: Comportamiento hacia el desarrollo del trabajo de grado, entendido no como \\
un requisito, sino en relación con las necesidades de la profesión y desde las formas y métodos peda- \\
gógicos de la educación científica en la actualidad. \\
Comunicación asertiva: Diálogo claro, preciso y respetuoso entre los participantes del proceso de \\
trabajo de grado, ya que la actitud es el valor que permite transmititr la información.
\end{tabular}

Fuente: Elaborada por los autores.

Con base en el análisis de las tres categorías de la investigación (tutorías, tutor y proceso de tutorías) se encontraron dos tipos de limitaciones. La primera tiene que ver con el quehacer pedagógico y la segunda con la gestión educativa. Asimismo, cuando estas se transversalizaron, se obtuvieron catorce categorías, de las cuales once corresponden al aspecto pedagógico: (1) Comunidad académica, (2) didáctica, (3) relación tutor-tutorado, (4) conocimiento de la profesión, (5) cultura de la investigación, (6) trabajo en equipo, (7) comunicación asertiva, (8) condiciones de trabajo, (9) coordinación y seguimiento, (10) crítica y autocrítica y (11) complementariedad en las formas de tutoría. Por su parte, desde la gestión educativa se generaron tres categorías: (1) Sistema de investigación formativa, (2) claridad sobre la investigación formativa y (3) actitud y motivación (figura 2). Se debe anotar que hay dos categorías que se repiten en la gestión educativa y en el ámbito pedagógico: Comunicación asertiva y coordinación y seguimiento, dos elementos que muestran que el desarrollo del trabajo de grado puede efectuarse de manera coherente y precisa.

Específicamente, las categorías definidas en el campo pedagógico se pueden sintetizar de la siguiente manera:

- Comunidad académica: Refleja la necesidad de fortalecer el diálogo y promover el efectivo desarrollo del proceso de trabajo de grado entre los actores involucrados

- Conocimiento pedagógico: Hace referencia a la necesidad de articular diferentes elementos en el marco del modelo pedagógico institucional.

- Didáctica: Evidencia la importancia de pensar y aplicar herramientas que permitan un efectivo proceso de acompañamiento al tutorado. 


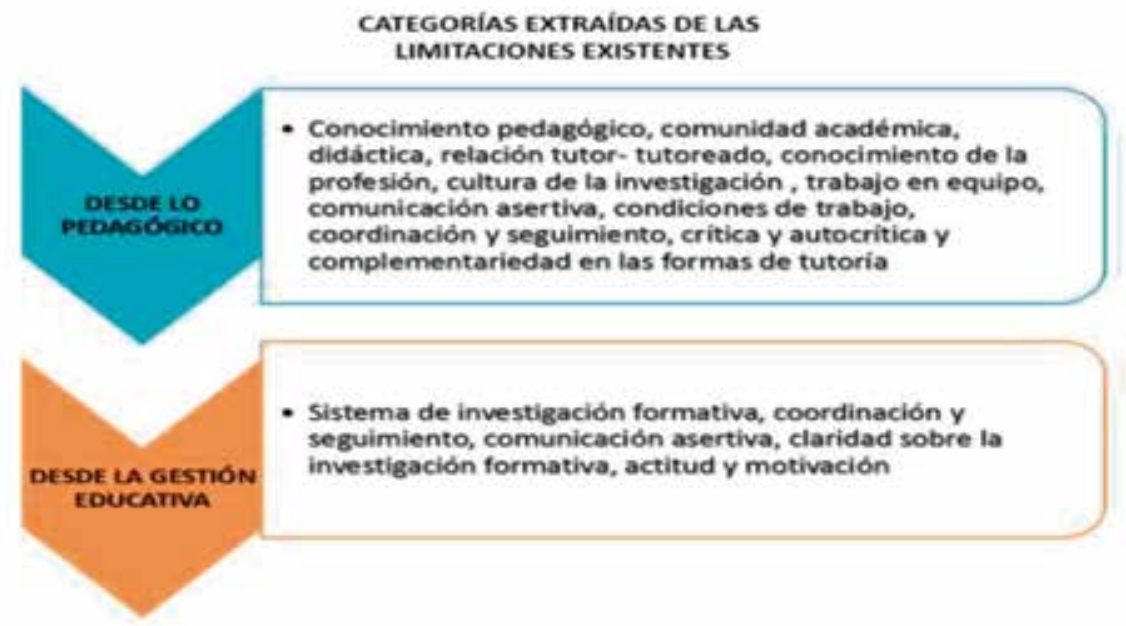

Figura 3. Categorías extraídas de las limitaciones existentes Fuente: Elaborada por los autores.

- La relación de tutor-tutorado: Implica que haya claridad en el rol de tutor y en el de estudiante, así como respecto a sus responsabilidades y compromisos educativos, entre otros.

- Conocimiento de la profesión sobre las ciencias militares: Fundamental para todos los actores, ya que generará el marco referencial en el cual se inscribe el problema de estudio.

- Cultura de la investigación: Evidencia diferentes tipos de relaciones, entre las cuales se encuentra la que se establece entre el ámbito disciplinar y el metodológico, así como entre los aspectos metodológicos generales, su especificidad asociada al objeto de investigación y las ciencias que lo sustentan, lo cual, a su vez, debe estar articulado con el diseńo y ejecución de la investigación

- Trabajo en equipo: Es una categoría fundamental, la cual no solo se da entre los estudiantes, sino que además incluye al tutor como líder del proceso.

- Comunicación asertiva: Pilar fundamental del hecho educativo, pues hace referencia al diálogo claro, preciso y respetuoso entre los diferentes actores involucrados.

- Condiciones de trabajo: Son todos aquellos elementos que permiten y facilitan el desarrollo del proceso de la investigación, en la cual deben participar el tutor y el estudiante, 
- Coordinación y seguimiento: Es el ejercicio permanente que debe hacer la coordinación de investigaciones de cada facultad para detectar deficiencias en el proceso y poderlas subsanar a tiempo.

- Crítica y autocrítica: Implica la objetividad para evaluar a los diferentes actores participantes, por una parte, y la capacidad para autoevaluarse, por otra, todo con el propósito de generar mejoras en el proceso.

- La complementariedad de las formas de tutoría: Surge de la necesidad de buscar nuevas formas de mantener una comunicación constante y fluida entre tutor y estudiantes, lo cual implica, entre otros aspectos, que se integre el uso de la virtualidad con la presencialidad para darle efectividad al proceso.

Por su parte, el sentido de las categorías sobre gestión educativa se presenta a continuación:

- Sistema de investigación formativa: Es el marco de acción, que implica el conjunto de procesos y acciones que orientan y permiten desarrollar el trabajo de grado.

- Claridad sobre la investigación formativa: Establece la base para desarrollar el trabajo de grado, pues marca el alcance del proceso.

- Actitud y motivación: Son el motor que condiciona al estudiante y al tutor a sentirse cómodos y con el estímulo necesario para desarrollar el trabajo de investigación, desde las formas y métodos pedagógicos de la educación científica en la actualidad.

Como se puede observar, desarrollar de forma efectiva un trabajo de grado implica articular una serie de variables. En este sentido, se comprende que es necesario contar con un robusto sistema de investigación que parta de la coherencia y la claridad, de tal manera que los dos actores principales del proceso (tutor y tutorado) cumplan con su objetivo de culminar satisfactoriamente el trabajo de grado conforme con los estándares establecidos por la institución.

$\mathrm{Al}$ hacer un comparativo con el estudio exploratorio de la primera etapa o primer proyecto de investigación, respecto a las limitaciones pedagógicas y de gestión educativa presentes en la investigación formativa, así como en relación con las competencias que se forman en la enseñanza y el aprendizaje del saber de Metodología de la Investigación, se observa que se repiten categorías tales como: Trabajo en equipo, didáctica, conocimiento y condiciones de estudio. No obstante, 
de que surgen en perspectivas de estudio distintas, estas categorías evidencian que existen limitaciones comunes en etapas diferentes del desarrollo del trabajo de grado, lo cual deberá contrastarse con la tercera etapa del proyecto para analizar su articulación y trazabilidad.

Con base en estos análisis, y como parte de un proceso de construcción pedagógica en el cual el tutor desempeña un papel preponderante en el fortalecimiento y la consolidación de aptitudes y actitudes investigativas en el estudiante, es posible construir una serie de competencias del tutor, las cuales son objeto del siguiente apartado.

\section{Propuesta de competencias de investigación que el tutor debe poseer para desarrollar en el estudiante durante el proceso de trabajo de grado}

Las competencias que se deben desarrollar en las tutorías para el trabajo de grado han sido pensadas y construidas desde las exigencias de los lineamientos del Sistema de Educación de las Fuerzas Armadas (Sefa), el modelo pedagógico de la formación del profesional en ciencias militares, los estados del arte actuales, las competencias de investigación formativa y la normatividad interna de la Esmic. Así mismo, desde las propuestas emergentes de los tutores y las limitaciones pedagógicas halladas en el estudio realizado.

Las competencias que debe desarrollar el tutor en las tutorías de trabajo de grado parten de entender que la tutoría es una práctica pedagógica sustentada en un conjunto de estrategias didácticas y metodológicas, las cuales permiten el acompañamiento y seguimiento del estudiante en el proceso de formación integral. Específicamente para este estudio de caso, la tutoría de trabajo de grado se puede realizar de diferentes formas y modalidades, de acuerdo con el contexto y las necesidades de formación. Desde esta perspectiva, la tutoría es inherente al quehacer docente e investigativo de todo profesor, pues en ella se orienta, controla y evalúa el trabajo independiente del estudiante y sus resultados a través de un plan de acción tutorial, que para el trabajo de grado consiste en el proyecto de investigación que se realiza. Además, es el producto de una concepción pedagógica, lo cual implica estrechas relaciones entre estudiantes y tutores de la institución para desarrollar la autonomía y el logro de competencias profesionales.

A continuación, se exponen las competencias que, idealmente, debería desarrollar un tutor durante su labor tutorial, en el entendido de que poseerlas, interio- 
rizarlas con la experiencia y aplicarlas como compromiso de vida contribuyen, muy seguramente, a que el estudiante de pregrado que aborda su proceso de investigación formativa las desarrolle y adquiera la cultura investigativa en su camino hacia la generación del conocimiento pertinente a la ciencia militar.

En coherencia con la manera en que el Proyecto Educativo del Programa de Profesionales en Ciencias Militares propone las competencias que debe desarrollar el futuro subteniente del Ejército Nacional de Colombia, es decir, en las dimensiones del Ser, Saber, Hacer y Convivir, en este apartado se hace una construcción similar, que se nutre de la esencia del mismo proyecto educativo, de fuentes externas y de la adaptación de las competencias genéricas que determina el Sefa en sus lineamientos para estudiantes, pero aplicadas a los tutores de trabajo de grado para su acción tutorial (tabla 4).

Tabla 5. Propuesta de competencias que se deben desarrollar en el proceso tutorial conforme con el modelo del profesional en ciencias militares

\begin{tabular}{|c|c|}
\hline \multicolumn{2}{|r|}{ Competencias deseables en el tutor para el proceso de los trabajos de grado } \\
\hline Dimensión del ser & $\begin{array}{l}\text { Sentido ético: } \\
\text { - Respeta las actitudes, creencias o conductas del estudiante. Asimismo, evita ejercer presiones inde- } \\
\text { bidas que desmotiven al nuevo investigador y limiten su creatividad e iniciativa. } \\
\text { - Se asegura de que los estudiantes citen las fuentes bibliográficas, autores e investigaciones consul- } \\
\text { tadas para la elaboración de su propio trabajo de grado. } \\
\text { - Motiva al estudiante a elaborar su trabajo de grado. Para esto complementa sus instrucciones como } \\
\text { tutor, sus reglas y sus métodos, con la participación y la consulta de otros expertos y la opinión del } \\
\text { mismo estudiante, permitiendo que tenga libertad para investigar. } \\
\text { - Afronta con entereza situaciones de conflicto entre personas y grupos con actitud constructiva y } \\
\text { sentido ético. } \\
\text { Liderazgo: } \\
\text { - Desarrolla en sus estudiantes evidentes sentimientos de confianza a partir de su conocimiento, expe- } \\
\text { riencia y habilidades comunicativas con el fin de influir positivamente en el cumplimiento de los obje- } \\
\text { tivos trazados. } \\
\text { Autocontroly adaptación: } \\
\text { - Adopta con facilidad actitudes que permitan el debate asertivo y no promuevan la confrontación } \\
\text { personal. } \\
\text { - Eomprende e interpreta las emociones de los estudiantes, de modo que puede desarrollar senti- } \\
\text { mientos de empatía sin perder la objetividad ni la autoridad que conlleva su labor tutorial. } \\
\text { - meneras confianza ante una posible falta de experiencia en las labores de tutoría, para lo cual controla } \\
\text { - Enivel de ansiedad. }\end{array}$ \\
\hline
\end{tabular}


110 Ideas y experiencias pedagógicas. Investigación formativa y la tutoría de trabajo de grado en la Educación Superior

\begin{tabular}{|c|c|}
\hline \multicolumn{2}{|r|}{ Competencias deseables en el tutor para el proceso de los trabajos de grado } \\
\hline Dimensión del ser & $\begin{array}{l}\text { Comunicación interpersonal: } \\
\text { - Expresa en todo momento críticas constructivas y respetuosas hacia sus estudiantes para generar } \\
\text { comprensión y colaboración en ellos. } \\
\text { - Adopta con facilidad actitudes que posibilitan la discusión y no promueven la confrontación personal. } \\
\text { - Propende por lograr una comunicación fluida, asegurándose de comprender satisfactoriamente los } \\
\text { requerimientos del estudiante y facilitando que este pierda el temor a preguntar, a confrontar, a } \\
\text { debatir, a expresarse. } \\
\text { - Defiende asertivamente y con habilidad sus posiciones y concilia con inteligencia. }\end{array}$ \\
\hline $\begin{array}{l}\text { Dimensión } \\
\text { del saber }\end{array}$ & $\begin{array}{l}\text { Aprender a desaprender: } \\
\text { - Acepta con agrado y de forma abierta la nueva información que recibe, analizando las diferentes pers- } \\
\text { pectivas y alternativas para generar otros aprendizajes en sus estudiantes. } \\
\text { - Acepta sus errores, aprende de ellos y analiza las críticas que recibe para mejorar su actuación en el futuro. } \\
\text { - Es capaz de reajustar sus modos de actuación y esquemas mentales, para aceptar lo que pudiera entrar } \\
\text { en contradicción con sus líneas de pensamiento profesional. } \\
\text { - Identifica y describe en detalle los fundamentos y la metodología que se aplican en los procesos de } \\
\text { investigación que promuevan la innovación tecnológica. } \\
\text { Uso de las TIC: } \\
\text { - Se preocupa por estar actualizado en el uso de las tecnologías de la información y la comunicación } \\
\text { como herramientas indispensables para la investigación bibliográfica. } \\
\text { Responsabilidad: } \\
\text { - Garantiza la disposición de tiempo de calidad para atender a los estudiantes y muestra en cada } \\
\text { encuentro, hasta finalizar su labor tutorial, cordialidad, sinceridad y afabilidad, lo cual contribuye a } \\
\text { afianzar un progresivo ambiente de confianza mutua. }\end{array}$ \\
\hline $\begin{array}{l}\text { Dimensión } \\
\text { del hacer }\end{array}$ & $\begin{array}{l}\text { Curiosidad intelectual: } \\
\text { - Guía al tutorando en la búsqueda de intereses académicos y vocacionales con el fin de que seleccione } \\
\text { el tema de investigación y concrete el tema específico para asegurar su motivación. } \\
\text { - Evidencia flexibilidad mental para abordar los contenidos desde la realidad global y luego enfocarlos } \\
\text { en el plano local. } \\
\text { Competencia docente: } \\
\text { - Posee sólidos conocimientos epistemológicos y metodológicos que le permiten guiar al estudiante en } \\
\text { el desarrollo de su trabajo de grado y está preparado o muestra interés para asesorarlo en la disciplina } \\
\text { o tema de la investigación. } \\
\text { - A partir de la continua observación, reconoce las fortalezas y debilidades en el estudiante asesorado, } \\
\text { con el fin de aprovechar su potencial hacia la mejora continua en su desarrollo personal. } \\
\text { Actitud creadora einnovadora: } \\
\text { - Motiva al estudiante a proponer temas de investigación novedosos, que respondan a las necesidades } \\
\text { propias de la profesión militar. } \\
\text { - Asesora al tutorando en la escogencia del tema, propone fuentes de información pertinentes y asesora } \\
\text { la construcción de instrumentos adecuados para asegurar una mejor calidad del trabajo. } \\
\text { - Tiene habilidad para identificar logros y limitaciones del trabajo con el fin de cuestionar, mejorar y dar } \\
\text { solución a los problemas planteados mediante alternativas racionales y efectivas. } \\
\text { - Está abierto al nuevo conocimiento y sus relaciones interdisciplinarias relacionadas con la formación militar. } \\
\text { - Comprende las estructuras del mundo y sus dinámicas con sensibilidad y creatividad. }\end{array}$ \\
\hline
\end{tabular}




\begin{tabular}{|c|c|}
\hline \multicolumn{2}{|r|}{ Competencias deseables en el tutor para el proceso de los trabajos de grado } \\
\hline $\begin{array}{l}\text { Dimensión } \\
\text { del hacer }\end{array}$ & $\begin{array}{l}\text { Autoaprendizaje: } \\
\text { - Estimula la iniciativa del estudiante para que busque el conocimiento a partir de su interacción con el } \\
\text { medio, además de que fomenta una personalidad constructiva e investigativa. }\end{array}$ \\
\hline & $\begin{array}{l}\text { Razonamiento crítico y abstracción: } \\
\text { - Promueve que el estudiante identifique ideas, conceptos y la representación del razonamiento de un } \\
\text { modo completo y organizado, para lo cual analiza de manera lógica los casos o situaciones reales con } \\
\text { el propósito de plantear soluciones y generar nuevas ideas. }\end{array}$ \\
\hline & $\begin{array}{l}\text { Pensamiento sistémico: } \\
\text { - Estimula en el estudiante la capacidad básica para procesar conocimientos específicos en diversas } \\
\text { situaciones y la habilidad de tomar contacto y comprender otras disciplinas. } \\
\text { - Ayuda a sus estudiantes a organizar e integrar adecuadamente componentes interrelacionados e } \\
\text { interdependientes para comprender el todo del proceso investigativo. }\end{array}$ \\
\hline & $\begin{array}{l}\text { Análisis de situaciones complejas: } \\
\text { - Integra adecuadamente elementos en una situación e identifica sus características y conexiones, dife- } \\
\text { renciando lo importante y lo secundario. } \\
\text { - Genera en el tutorando las habilidades necesarias para determinar el impacto de cada una de las alter- } \\
\text { nativas planteadas como solución a una problemática. }\end{array}$ \\
\hline & $\begin{array}{l}\text { Evaluación: } \\
\text { - Evalúa en forma permanente y oportuna los resultados del proceso investigativo, determinando posi- } \\
\text { bles desviaciones metodológicas y disciplinares para que el estudiante haga los ajustes necesarios y } \\
\text { resuelva la pregunta problema y los objetivos que se formuló en la investigación. } \\
\text { - Emite juicios de valor, con objetividad y observaciones fundamentadas sobre el progreso del ejercicio } \\
\text { investigativo, reconociendo aciertos y señalando errores en forma asertiva con el fin de no afectar el } \\
\text { entusiasmo del tutorando. }\end{array}$ \\
\hline $\begin{array}{l}\text { Dimensión } \\
\text { del convivir }\end{array}$ & $\begin{array}{l}\text { Interculturalidad: } \\
\text { - Interactúa dentro de la diferencia de culturas de sus estudiantes, de manera que favorece en todo } \\
\text { momento la integración y la sana convivencia, basada en el respeto a la diversidad y el enriqueci- } \\
\text { miento mutuo. }\end{array}$ \\
\hline & $\begin{array}{l}\text { Trabajo en equipo: } \\
\text { - Dirige los grupos de trabajo fomentando el compromiso con la lectura, la investigación y el respeto } \\
\text { por el método sistemático. } \\
\text { - Reformula los procedimientos para lograr los objetivos propuestos y generar una fuerte adhesión de } \\
\text { los equipos de trabajo. }\end{array}$ \\
\hline
\end{tabular}

Fuente: Elaborada por los autores.

En síntesis, la labor del tutor de trabajo de grado es más que una mera responsabilidad de trámite, algo nominal. La institución y, puntualmente, el estudiante espera de un tutor que posea unas competencias de tipo ético, actitudinal, comportamental, conocimientos, experticia docente y evidentes habilidades para que dirija el proceso de investigación formativa, mediante el cual será posible verificar teorías, así como resolver problemas propios de la ciencia militar. Finalmente, también se cuenta con que este tutor descubra, promueva y fortalezca en cada tutorando 
las destrezas básicas que lo animen a desarrollar de forma sistemática y progresiva la capacidad de intelectual para la observación que lleva al descubrimiento, la iniciativa para la búsqueda de información y la actitud permanente para crear con originalidad nuevas cosas que mejoren efectivamente la realización de las tareas o proyectos académicos o profesionales que emprenda.

\section{Conclusiones}

Existen limitaciones pedagógicas y de gestión educativa en el proceso de desarrollo de las tutorías para el trabajo de grado que deben ser conocidas por la comunidad académica, para que esta pueda debatirla y proponer soluciones desde sus diferentes contextos educativos. En este sentido, se debe tener presente que el desarrollo de los trabajos de grado implica la articulación de acciones en diferentes ámbitos educativos que se complementan, como son el conocimiento pedagógico, disciplinar y profesional; la comunidad académica con comunicación asertiva; las relaciones interpersonales; el trabajo en equipo; las condiciones de trabajo; la capacidad de crítica y autocrítica; la cultura de la investigación, entre otras. Asimismo, es necesario que exista un sistema de investigación formativa con claridad, coordinación y seguimiento, entre otras características. Estos criterios son fundamentales para que los dos sujetos principales del proceso (tutor y tutorados) puedan cumplir con motivación y compromiso el objetivo de culminar un trabajo de grado de calidad que esté acorde con los estándares establecidos por la institución.

Desde esta perspectiva, también es necesario que el modelo pedagógico deje de ser un documento de frías intencionalidades, ajeno a la comunidad académica y a la realidad educativa del contexto formativo. Es decir, no debe ser un documento que muestre sapiencia y actualización pedagógica, mucho menos que sea una copia de lo que otras instituciones repiten y no hacen. Por el contrario, debe concretar el ideal de formación, una prospectiva en construcción diaria desde la formación profesional y sus requerimientos de cambio, tanto en las aulas como en la práctica.

La falta de transversalidad entre el modelo pedagógico, las competencias profesionales, el diseño curricular, los contenidos y la didáctica es el principal problema que afronta la institución para integrar las funciones sustantivas de esta formación, desde la gestión institucional y la actividad pedagógica de los profesores e investigadores. Además, el aislamiento académico en la investigación educativa limita la aplicación de las competencias en los procesos de enseñanza aprendizaje.

En este sentido, la propuesta de formular competencias de investigación formativa en el proceso tutorial de trabajo de grado se hace desde el modelo peda- 
gógico de la formación del profesional en ciencias militares — actualizado desde el perfil profesional— $\mathrm{y}$ los diferentes aspectos que señalaron los tutores y estudiantes en el estudio diagnóstico realizado. Asimismo, se debe destacar que este resultado es una respuesta necesaria a la falta de definición y de una orientación clara sobre las competencias que se deben desarrollar en las tutorías para el trabajo de grado y que impide esclarecer acciones, roles, responsabilidades y tareas en este proceso. En consecuencia, la propuesta constituye un primer acercamiento que debe ser mejorado con la participación de la comunidad académica, ya que la labor del tutor de trabajo de grado es más que una mera responsabilidad de trámite, algo nominal.

Finalmente, se concluye que del tutor se esperan competencias de tipo ético, actitudinal, comportamental, conocimientos, experticia docente y evidentes habilidades para dirigir el proceso de investigación formativa, mediante el cual será posible verificar teorías y resolver problemas propios de su área de conocimiento. Asimismo, se cuenta con que este tutor descubra, promueva y fortalezca en cada tutorando las destrezas básicas que lo animen a desarrollar de forma sistemática y progresiva la capacidad intelectual para la observación que lleva al descubrimiento, la iniciativa, la búsqueda de información y la actitud permanente para crear con originalidad nuevas cosas que mejoren efectivamente la realización de las tareas o proyectos académicos o profesionales que emprenda.

\section{Bibliografía}

Álvarez, V. (2004). Las tutorías: Otra forma de enseñar en la universidad [documento en línea]. Recuperado de campus.usal.es/ ofeees/PONENCIAS_TUTORIA/Victor\%20Alvarez\%20Rojo.pdf

Arana Ercilla. M. H., Acosta Arévalo, C, Ibarra Argoty, V. H., Latorre Rojas, E. J., Pérez Ferro, L. C., Mendoza Gómez, M. \& Galindo, J. A. (2013). Educación cientifica y cultura investigativa para la formación del profesional en ciencias militares de Colombia. Bogotá: Escuela Militar de Cadetes "General José María Córdova”.

Arana Ercilla. M. H., Acosta Arévalo, C, Ibarra Argoty, V. H., Latorre Rojas, E. J., Pérez Ferro, L. C., Mendoza Gómez, M. \& Galindo, J. A., Reyes García, D., Mendoza Bonilla, B., Gómez Parrado, L., Muñoz Angulo, L.G. (2018). Educación científica y cultura investigativa en Ciencias Militares. Segunda Edición. Bogotá: Escuela Militar de Cadetes "General José María Córdova”.

Arana Ercilla. M. H., Rodríguez Bernal, Y., (2007). Ciencia, tecnología y sociedad en la formación de educadores infantiles. Revista Innovación y Ciencia, Volumen XIV. No.2, Asociación Colombiana para el Avance de la Ciencia

Arnheim, R. (1985). El pensamiento visual. Buenos Aires: Eudeba.

Capelari, M. I. (2009). Las configuraciones del rol del tutor en la universidad argentina: aportes para reflexionar acerca de los significados que se construyen sobre el fracaso educativo en la educa- 
ción superior. Revista Iberoamericana De Educación, 49(8), 1-10. Recuperado de https://rieoei. org/RIE/article/view/1985

Coromoto, M. (2009). Labor del tutor y asesor. Experiencias e incentivos. Revista Educere, 13 (47), 919-930. Recuperado de http://www.redalyc.org/pdf/356/35616673004.pdf

Durán, D. \& Huerta, V. (2008). Una experiencia de tutoría entre iguales en la universidad mexicana de Oaxaca. Revista Iberoamericana de Educación, 48 (1). Recuperada de https://rieoei.org/RIE/ article/view/2262

Escuela Militar de Cadetes "General José María Córdova” [Esmic]. (2018). Proyecto Educativo del Programa "Profesional en Ciencias Militares".

Goldstein, E. B. (1999). Sensaciones y percepciones (5. a ed.) University of Pittsburg.

Hernández, C. A., Jiménez, M., Guadarrama, E. \& Rivera. Á. E. (2016). La percepción de la motivación y satisfacción de la tutoría recibida en estudios de posgrado. Formación Universitaria, 9 (2), 49-58. Recuperado de https://scielo.conicyt.cl/pdf/formuniv/v9n2/art06.pdf

Ladino J. M. (2015). Enfoques y tendencias de la gestión en la educación en Colombia. Percepciones de directivos docentes estudiantes de maestría de dos universidades públicas de Bogotá. (Tesis de maestría en Educación). Universidad Pedagógica Nacional de Colombia, Bogotá.

Latorre, J. (2016). Evaluación de la cultura de la investigación en la Facultad de Ciencias Militares desde el modelo y sistema de gestión de la investigación [informe de investigación]. Bogotá: Escuela Militar de Cadetes "General José María Córdova”.

Llinás, R. (1999). La percepción y el ensueño. Revista Innovación y Ciencia, 8 (4), 102-112.

Lobato, C. et al. (2005). Las representaciones de la tutoría universitaria en profesores y estudiantes: Estudio de un caso. International Journal of Psychology and Sychological Therapy, 5 (2), 145-164.

Martínez, P., Martínez, M. \& Pérez, J. (2016). ¿Cómo avanzar en la tutoría universitaria? Estrategias de acción: Los estudiantes tienen la palabra. Revista Española de Orientación y Psicopedagogía, 27, (2), 80-98. Recuperado de http://revista.uned.es/indexp.php/recop/article/view

Morgado, I. (2009). Psicobiología de la consciencia: Conceptos, hipótesis y observaciones clínicas y experimentales. Revista de Neurología, 49 (5), 251-256.

Morgado, I. (2012). Cómo percibimos el mundo. Una exploración de la mente y los sentidos. Barcelona: Ariel.

Organización de Estados Iberoamericanos para la Educación, la Ciencia y la Cultura [OEI] \& Red Iberoamericana de Indicadores de Ciencia y Tecnología [Ricyt]. (2003). Proyecto Iberoamericano de Indicadores de percepción pública, cultura científica y participación ciudadana. Revista Iberoamericana de Ciencia, Tecnología, Sociedad e Innovación de la OEI, 5. Recuperado de http:// www.oei.es/revistactsi/numero5/documentos1.htm.

Pámies, M. A. \& Galindo, C. F. (2015). Tutoría como herramienta académica del desarrollo de competencias transversales, 68 (1), 165-178.

Pabón, L. C. et al. (2009). Estrategias pedagógicas como herramienta educativa: La tutoría y el proceso formativo de los estudiantes. Revista Iberoamericana de Educación, 50 (3).

Rangel, P. J. \& Jiménez, E. (2016). Un modelo alternativo para aprender a investigar en el posgrado. (Tesis de grado). Universidad Simón Rodríguez, Caracas. 
Redes. (2003). Resultados de la Encuesta de Percepción Pública de la Ciencia realizada en Argentina, Brasil, España y Uruguay. Documentos de Trabajo, 9. Recuperado de http://www.ricyt.org/interior/biblioteca/docs/percepcion.pdf.

Rojas, M. O. (2009). Estrategias pedagógicas como herramienta educativa: la tutoría y el proceso formativo de los estudiantes. Revista Iberoamericana de Educación O.E.I., Vol.50, Num.3, Recuperado de https://rioei.org/REI/article/view/1869.

Rosas, A. K., Flores, D. \& Valarino, E. (2006). Rol del tutor de tesis: Competencias, condiciones personales y funciones. Investigación y Postgrado, 21 (1), 153-185. Recuperado de http://www. scielo.org.ve/scielo.php?script=sci_arttext\&pid=S1316-00872006000100007

Venegas, J. M. y Del Río, J. E. (2010). Estilos docentes y acción tutorial y orientadora. Revista Iberoamericana de Educación, 52 (6). 1-16. Recuperado de https://rieoei.org/historico/deloslectores/3462Roa.pdf

Zúñiga, M. (noviembre de 2014). La experiencia del modelo tutorial en la educación para una cultura científica de los alumnos y alumnas con aptitudes sobresalientes de secundaria. Ponencia presentada en el Congreso Iberoamericano de Ciencia, Tecnología, Innovación y Educación, Buenos Aires, Argentina. www.oei.es/historico/congreso2014/memoriactei/709.pdf 